\title{
An assessment of clinic based family planning services in Kenya: Results from the 1995 situation analysis study
}

\author{
Lewis Ndhlovu \\ Population Council \\ Julie Solo \\ Population Council \\ Robert A. Miller \\ Population Council \\ Kate Miller \\ Population Council \\ Achola Ominde
}

Follow this and additional works at: https://knowledgecommons.popcouncil.org/departments_sbsr-rh

Part of the Health Services Research Commons, and the International Public Health Commons How does access to this work benefit you? Let us know!

\section{Recommended Citation}

Ndhlovu, Lewis, Julie Solo, Robert A. Miller, and Kate Miller. 1997. "An assessment of clinic based family planning services in Kenya: Results from the 1995 situation analysis study," Africa OR/TA Project II.

Nairobi: Population Council. 


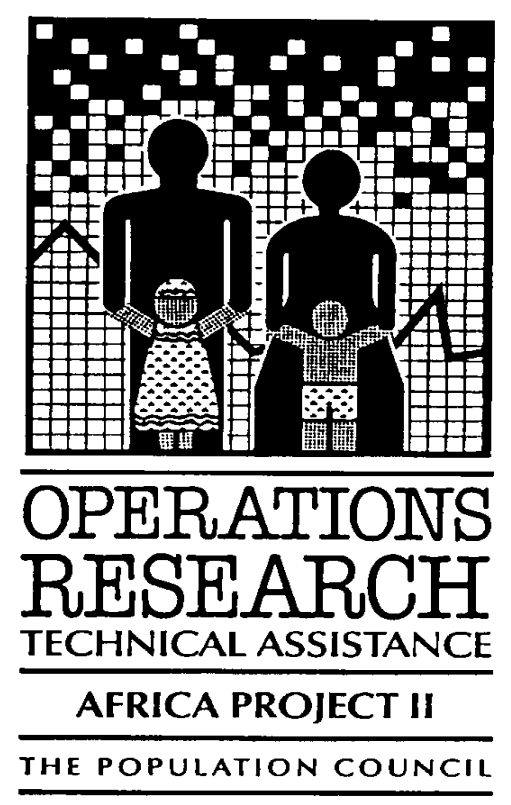

\title{
AN ASSESSMENT OF CLINIC-BASED FAMILY PLANNING SERVICES IN KENYA:
}

\author{
RESULTS FROM THE 1995 \\ SITUATION ANALYSIS STUDY
}

\author{
The Africa OR/TA Project II \\ The Population Council \\ Lewis Ndhlovu \\ Julie Solo \\ Robert Miller \\ Kate Miller
}

Division of Family Health, Ministry of Health

Achola Ominde

January , 1997 


\section{The Population Council}

The Population Council seeks to help improve the well-being and reproductive health of current and future generations around the world and to help achieve a humane, equitable, and sustainable balance between people and resources. The Council analyzes population issues and trends; conducts biomedical research to develop new contraceptives; works with public and private agencies to improve the quality and outreach of family planning and reproductive health services; helps governments to influence demographic behavior; communicates the results of research in the population field to appropriate audiences; and helps build research capacities in developing countries. The Council, a nonprofit, nongovernmental research organization established in 1952, has a multinational Board of Trustees; its New York headquarters supports a global network of regional and country offices.

\section{Africa OR/TA Project II}

The overall objectives of the Africa OR/TA Project II are to broaden understanding of how to improve family planning services in Sub-Saharan Africa, and to apply operations research and technical assistance to improve services by:

- $\quad$ increasing access to a full range of family planning services and methods;

- $\quad$ developing service delivery strategies that are client-oriented and acceptable to various population groups;

- $\quad$ improving the operations of programs to make them more efficient and financially sustainable;

- $\quad$ improving the quality of services;

- $\quad$ strengthening the capabilities of family planning program managers to use operations research to diagnose and solve service delivery problems.

This study was supported by The Population Council's Africa Operations Research and Technical Assistance Project II. The Africa OR/TA Project II is funded by the U.S. Agency for International Development (A.I.D), Office of Population Contract No. CCC-3030-C-00-3008-00, Strategies for Improving Family Planning Service Delivery. 
TABLE OF CONTENTS

\section{ACKNOWLEDGMENTS}

..............................

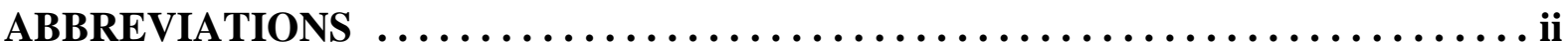

EXECUTIVE SUMMARY $\ldots \ldots \ldots \ldots \ldots \ldots \ldots \ldots \ldots \ldots \ldots \ldots \ldots \ldots \ldots \ldots \ldots \ldots$

I. THE KENYA FAMILY PLANNING PROGRAMME $\ldots \ldots \ldots \ldots \ldots \ldots \ldots \ldots$

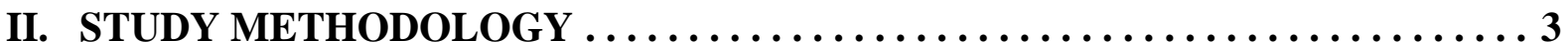

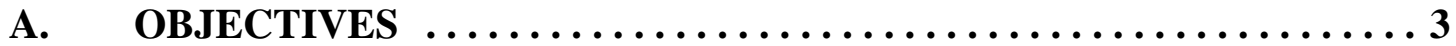

B. SAMPLING CLINICAL HEALTH FACILITIES $\ldots \ldots \ldots \ldots \ldots \ldots . \ldots$

C. DATA COLLECTION $\ldots \ldots \ldots \ldots \ldots \ldots \ldots \ldots \ldots \ldots \ldots \ldots$

D. SAMPLE CHARACTERISTICS $\ldots \ldots \ldots \ldots \ldots \ldots \ldots \ldots \ldots$

III. KEY FINDINGS AND PROGRAMMATIC RECOMMENDATIONS $\ldots \ldots \ldots 8$

A. ACCESS TO FAMILY PLANNING SERVICES $\ldots \ldots \ldots \ldots \ldots \ldots$.

B. VOLUME OF SERVICES PROVIDED

AT HEALTH FACILITIES . . . . . . . . . . . . . . . . 11

C. FUNCTIONING OF HEALTH FACILITY SUBSYSTEMS $\ldots \ldots \ldots 12$

D. QUALITY OF CARE $\ldots \ldots \ldots \ldots \ldots \ldots \ldots \ldots \ldots \ldots \ldots \ldots \ldots$

IV. A COMPARISON OF THE MOH FAMILY PLANNING

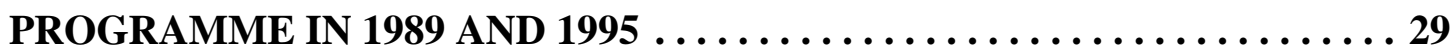

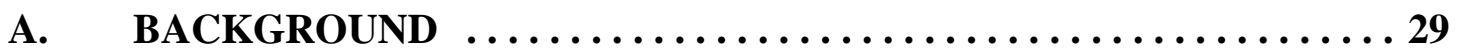

B. SUMMARY OF FINDINGS FROM THE 1989 STUDY .......... 29

C. COMPARISON OF THE 1989 AND 1995 SITUATIONS $\ldots \ldots \ldots \ldots 30$

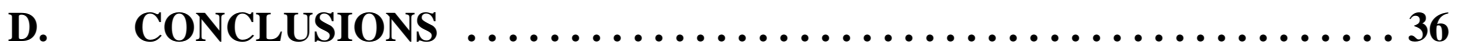

V. DISSEMINATION AND UTILIZATION OF THE STUDY RESULTS . . . . . 37

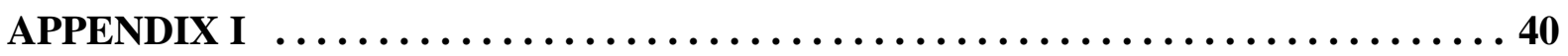

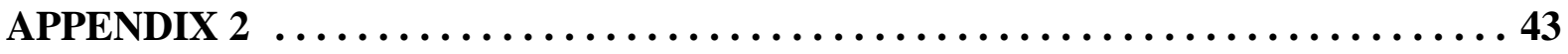




\section{ACKNOWLEDGMENTS}

This study was undertaken with substantial technical assistance from a number of people and organizations. We acknowledge the dedicated work of the field supervisors and investigators (listed in Appendix 2) who traveled over 35,000 kilometres to reach the different hospitals, health centres and dispensaries in the country. The Ministry of Health of the Government of Kenya, the Christian Health Association of Kenya, the Family Planning Association of Kenya and Population Health Services facilitated visits to their health facilities. Finally, contributions to the preparation of the report were made through the Data Interpretation Workshop, held in September 1995, the Dissemination Seminar held in March, 1996, and through numerous discussions with staff from these organizations, and from USAID and Pathfinder International. All these contributions are kindly acknowledged. 


\section{ABBREVIATIONS}

AIDS

BP

CBD

CHAK

COC

$\mathrm{DFH}$

FP

FPAK

GOK

HIV

IEC

IUD

KDHS

$\mathrm{MCH}$

$\mathrm{MOH}$

NCC

NCPD

NGO

OR

POP

RTI

SA

SDP

SPSS

STD

STI

TFR

USAID
Acquired Immune Deficiency Syndrome

Blood Pressure

Community Based Distribution

Christian Health Association of Kenya

Combined Oral Contraceptives

Division of Family Health

Family Planning

Family Planning Association of Kenya

Government of Kenya

Human Immunodeficiency Virus

Information, Education and Communication

Intra-uterine Device

Kenya Demographic and Health Survey

Maternal Child Health

Ministry of Health

Nairobi City Council

National Council for Population and Development

Non Governmental Organisation

Operations Research

Progestin Only Pill

Reproductive Tract Infection

Situation Analysis

Service Delivery Point

Statistical Package for Social Scientists

Sexually Transmitted Diseases

Sexually Transmitted Infections

Total Fertility Rate

United States Agency for International Development 


\section{EXECUTIVE SUMMARY}

The ultimate objective of this study was to assist the Kenya Ministry of Health (MOH), the National Council for Population and Development (NCPD), NGOs and donor agencies to plan the expansion and improvement of family planning and other reproductive health services provided in Kenya. Data on the functioning of programme subsystems and the quality of care provided were collected in May 1995 from $254 \mathrm{MCH} / \mathrm{FP}$ facilities throughout the country using the Situation Analysis approach. The study sample included a representative sample of facilities from the $\mathrm{MOH}$ and NGO sectors. It also included a census of all facilities operated by the Nairobi City Council (NCC) so that comparisons could be made with the Situation Analysis study undertaken in 1991. Data were collected through an inventory of facility infrastructure and equipment, staff interviews, observations of family planning client-provider consultations, and exit interviews with family planning and $\mathrm{MCH}$ staff. This is the second time that a national Situation Analysis study has been undertaken in Kenya, and a comparison was made with the results from the first study which was undertaken in 1989.

The principal findings and recommendations for strengthening the $\mathrm{MCH} / \mathrm{FP}$ programme are as follows:

\section{I) Access to services}

- The vast majority of facilities usually provide oral contraceptives, condoms and the injectable, and many provide the IUD.

- A much larger proportion of NGO facilities offered RTI/STI and HIV/AIDS services than either the Government or the NCC facilities.

- $\quad$ Over half of the facilities had no visible sign announcing the availability of family planning services.

- Half of the facilities began seeing clients more than one hour after the opening time

- The majority of facilities with stockout problems are located in the rural areas.

- $\quad$ Clients take, on average, three-quarters of an hour to get to the facility and most women felt that their waiting time was reasonable.

\section{Recommendations for improving access to services}

1) Facility managers should clearly publicize all services available at the facility through better use of signs.

2) Facility managers need to review and revise the scheduling of daily activities at their facilities so that they start and finish closer to official opening hours. At the busier clinics this should include encouraging clients (and providers) to attend for service delivery throughout the day to reduce congestion in the morning. 
3) Although most facilities regularly provide at least four contraceptive methods and stockouts for these methods are not too much of a problem, efforts could be made to broaden the range of methods available by increasing the provision of natural family planning and, in certain facilities, the diaphragm.

4) Clients currently pay nothing or very little for family planning services. Almost all of those that did pay felt that it the amount was acceptable, which suggests that a costrecovery scheme for family planning could be introduced if carefully planned.

\section{II) Readiness of facilities to provide reproductive health services}

- $\quad$ Availability of piped water and electricity is a problem at many health facilities.

- $\quad$ Most facilities appear to be fairly well equipped.

- $\quad$ Only 16 percent of facilities had the full range of sterilizing equipment, lotion and gloves to be able to prevent infection, but the vast majority of facilities had at least two of these items.

- $\quad$ Only one half of the facilities that stocked Depo Provera were found to have both needles and syringes available.

- Health talks were held at only 22 percent of Government facilities and 36 percent of NCC facilities.

- $\quad$ Most MCH/FP units have at least one poster about family planning and/or child welfare and very few clients stated that they had ever taken any educational materials home.

- $\quad$ Only one third of MCH clients reported that they had seen or heard anything about family planning during the course of their visit, and this was mostly through seeing a poster (66 percent), although one quarter said that family planning had been discussed with them during their $\mathrm{MCH}$ consultation.

- A small group of health facilities do make a concerted effort to educate their clients using a combination of IEC materials and health talks.

- $\quad$ Approximately two thirds of facilities are being supervised in accordance with MOH policy (i.e. once every three months), and the supervisory actions taken appear to be quite good, with two thirds of supervisors asking about problems, and almost half the supervisors observing several services during one visit.

- $\quad$ The staff are generally well experienced and qualified, with an average of four years work experience since their basic training

- Over three quarters of facilities had a written inventory for family planning commodities, whereas fewer had inventories for immunization vaccines and RTI/STI drugs. 
- More than one third of the facilities had commodities that were not stored according to expiration dates

- $\quad$ One quarter of facilities had some missing records.

\section{Recommendations for improving subsystem functioning}

1) The lack of basic equipment and supplies in some facilities should be addressed by the relevant managing authorities. Recommended standard practices require that all new family planning clients receive a full medical examination (including taking blood pressure, weight and a pelvic examination), and so the availability of gloves, blood pressure and weighing machines should be guaranteed at all facilities.

2) To improve clients' choice of contraceptive methods, all contraceptive commodities for the services being offered, including IUDs, injectables and spermicides, and their supporting supplies and equipment (e.g. needles, syringes, etc) should be made available at all health facilities at all times.

3) Given that many women cite the clinic as the first and main source of family planning information, a concerted effort should be made to undertake daily group talks and discussions for clients (using good quality visual materials to illustrate clear themes), and to include discussions of other relevant services during individual consultations when providing MCH or FP services. Attention could be paid to developing specially tailored and packaged IEC material(together with supporting training) that could be used when giving daily health talks and during individual consultations.

4) Very few family planning and MCH clients receive educational materials to take away, even when they are available. Wherever possible, staff should be encouraged to distribute existing materials to literate clients, and efforts could be made to produce more materials and make them available to providers.

5) Overall the frequency and type of supervision is satisfactory, although the proportion of facilities not receiving any supervisory visits has not decreased since 1989. Supervisory activity reports should be compiled regularly and fed back to facility staff.

6) For MCH/FP providers to play a role in preventing and managing RTI/STIs and HIV AIDS, a strong effort must be made to develop and provide appropriate post basic training in these services, particularly in relation to risk assessment and screening.

7) Greater efforts need to be made to ensure that commodities are correctly stored.

8) Staff need to be trained in the proper maintenance of client records and in their use for planning purposes. A more integrated approach to maintaining records on different reproductive health services should be developed to reduce the overburdened recording system. 


\section{III) Quality of Care}

- $\quad$ The vast majority of both family planning and $\mathrm{MCH}$ clients were satisfied overall with their visit, and felt that they received the information and services that they wanted. Most clients felt that the consultation time was satisfactory.

- In some cases, resupply clients would have preferred a more in-depth discussion of their method use.

- $\quad$ Most new clients were told about six methods on average.

- The most frequently imposed restriction is requiring a client to have at least one child.

- $\quad$ Most new clients were asked their reproductive intentions.

- Whether a client had discussed family planning with her partner was asked in only a little over half of the interactions.

- Apart from asking one third of new clients about the nature of their sexual relations, most were seldom asked any risk assessment questions.

- In only 12 percent of consultations were new family planning clients explicitly told that condoms can protect against STIs/HIV.

- In most cases, the provider explained to the new client how to use the selected method, but many women were not properly informed about side effects or their management.

- $\quad$ IEC materials seems to be an underutilized method of information exchange.

- Most new and revisit clients had their weight and blood pressure taken, while a substantial proportion of new clients had breast and pelvic examinations.

- Only eight percent of providers thought it necessary to screen new IUD clients for RTI/STIs.

- Almost all family planning clients were told when to return for resupply or follow-up

- $\quad$ Almost all clients had heard of HIV/AIDS, but gonorrhea and syphilis were the only other STIs that a significant number could name. Almost all clients could name at least one symptom suggestive of an STI. 


\section{Recommendations for strengthening the quality of care provided}

1) While clients express high levels of satisfaction with the service received, observations by the researchers and findings from a previous research study suggest that the interpersonal skills of some providers could be improved. For some clients, especially a significant proportion of revisit clients, the time spent with the provider was insufficient, and so providers should ensure that clients are given enough time to discuss all their concerns.

2) Influenced by the currently available policy guidelines, the vast majority of providers impose a requirement that a woman must have at least one child before she can use any form of contraception, and substantial proportions require that a woman be married and have spousal consent. It is understood that the guidelines are being revised to remove references to these restrictions, but it is essential that all providers are well informed that such requirements are unnecessary barriers to using contraception.

3) The role of the IUD as a long-term method needs to be reinforced as many providers do not recommend its use for this purpose.

4) In assessing a client's needs, providers must pay more attention to asking questions that assess the client's risk of infection and screen for possible symptoms.

5) In many counselling sessions women are not being informed about the side effects of the method they have accepted or about how to manage them. This aspect of counselling needs to be strengthened when training staff and during routine supervision.

6) Only two-thirds of new clients were given a breast examination; given that this is a lowcost intervention that can be easily used to screen for a possible cancer, the importance and correct way to undertake breast exams should be reinforced during staff training and supervision.

7) In all clinics generally, and in the NCC clinics in particular, there is an encouraging trend towards increased discussion of other reproductive health topics during the family planning consultation. This trend should be promoted and strengthened, through encouraging staff to pro-actively ask clients about other reproductive health topics, especially STIs, HIV/AIDS, breastfeeding and other child health issues. Some staff may require update training in some of these topics. 


\section{IV) Changes in the programme since 1989:}

For most of the issues examined, the indicators suggest that the Kenya programme is functioning better, and the quality of care has improved, although room for further improvement remains in the following aspects:

- $\quad$ Increased availability of Depo Provera, Norplant ${ }^{\circledR}$ implants, and possibly sterilization.

- $\quad$ The IEC programme appears to have been strengthened in terms of availability of educational materials, but not in terms of health talks provided to waiting clients.

- $\quad$ No significant changes in the frequency of supervision provided.

- A dramatic increase in the proportion of nurses who received in-service training.

- A substantial shift toward visits to supply Depo Provera and away from visits for the supply of oral contraceptives.

- An increase in the proportion of clients hearing about tubal ligation and vasectomy, and a decrease in the proportion of clients hearing about foam/spermicides

- $\quad$ A rise in the number of methods mentioned to clients.

- More clients hearing about side effects and their management, fewer clients hearing about the benefits of methods, and about the same proportion of clients hearing about how to use methods.

- The proportion of clients who were observed to hear about at least one other health issue during their consultation increased significantly from 15 percent to 35 percent.

Programme managers and representatives of technical assistance and donor agencies were involved in the design and implementation of the study, and in the interpretation and utilization of the results. The results have been presented at both a Data Interpretation Workshop and a National Dissemination Seminar, and plans are underway for disseminating the results to the provincial level for MOH programme staff. The NCC has held a workshop to review the findings for its facilities and to assess progress since the 1991 Situation Analysis study. 


\section{THE KENYA FAMILY PLANNING PROGRAMME}

In the period 1967-1984, Kenya had one of the highest total fertility rates (TFR) and population growth rates in the world. The TFR was about 8 in the late 1970s, and the rate of population growth, which had been increasing for decades as infant and child mortality declined, was estimated at 3.2 in 1990. ${ }^{1}$ While the current TFR at 5.4 is still considered high, it has been declining rapidly, especially in the 1989 - 1993 period. $^{2}$ The national contraceptive prevalence rate has reached one of the highest levels in Africa; in 1993, 27 percent of currently married women were using modern family planning methods -- a nine percent increase since 1989. While demographers had been pessimistic about the prospects for fertility decline in Kenya (and most of Africa) for decades, Kenya now is thought to have begun a demographic transition. ${ }^{3}$ Government policies that can be credited with contributing to the fertility decline include those in education, health, communication, transportation, and land tenure, all of which helped Kenyans "... In a single generation, ...(to) become literate, geographically mobile, consumer goods-oriented, health-seeking economic beings." 4

The Ministry of Health's family planning programme, implemented by the Division of Family Health, with overall programme and policy coordination by the National Council for Population and Development (NCPD), is credited with having contributed to this recent dramatic fertility decline. The Government programme, which begun in 1967 has, until recently, been subjected to some criticism, ${ }^{5}$ but in 1989 , based on evidence from the first Situation Analysis study, it was suggested that the programme could be better characterized as "moderate" rather than "poor" or "weak"- terms that had been used previously:

"This overall "moderate" rating carries with it the appropriate implication that the Kenyan programme both has made substantial progress in recent years and still has a long way to go."

$1 \quad$ Kenya Government " National Development Plan for the Period 1994 to 1996." Nairobi.

2 National Council for Population and Development (NCPD), Central Bureau of Statistics (CBS), Office of the Vice President and Ministry of Planning and National Development [Kenya], and Macro International Inc.(MI), 1994. " Kenya Demographic and Health Survey 1993." Calverton, Maryland: NCPD, CBS, and MI.

3 Robinson, W.C. "Kenya enters the fertility transition." Population Studies 46(4), 1992, 445-457.

$4 \quad$ Page 135 in Brass, William and Carole L. Jolly ed." Population Dynamics of Kenya." Washington: National Academy Press, 1993.

5 Henin, R., Kenya's population program 1965-1985: An evaluation, Unpublished manuscript, Nairobi, The Population Council, 1986; also Lapham, R. and W. P. Mauldin, Measuring family planning program effort in developing countries, 1972 and 1982, in The effects of family planning programs on fertility in the developing world, Nancy Birdsall (ed.), World Bank staff working paper no. 677, Washington, D.C., The World Bank, 1985.

6 Miller, R., L. Ndhlovu, M. Gachara, and A. Fisher, Situation Analysis study of Kenya's family planning program, in A. Jain (ed.), Managing quality of care in population programs, Kumarian Press, West Hartford, 1992. 
Indeed, the 1993 Kenya Demographic and Health Survey (KDHS) found that 68 percent of contraceptive users report the Government programme as the source for their contraceptives -- including 30 percent from Government hospitals, 25 percent from Government health centres, and 14 percent from Government dispensaries.

The Kenyan family planning programme is implemented through 966 public sector clinical health facilities, which are supported by over $380 \mathrm{NGO} /$ private facilities. $^{7}$ Additionally, there is a community based distribution (CBD) network developed by more than 25 government and non-governmental agencies providing services in seven of eight provinces. ${ }^{8}$

Strengths and weaknesses of the Government's family planning programme, including the functioning of subsystems and the quality of care provided and received, were first assessed in 1989 through the Situation Analysis approach"; this was the first time the approach had ever been used. In 1991, this same methodology was used to assess the family planning services delivered by the 46 Nairobi City Council health facilities. ${ }^{10}$ The study reported here has taken a second look at both the national programme and the Nairobi City Council programme, again using the Situation Analysis approach, to assess the functioning and quality of services provided. The first part of this report briefly describes the data collection methodology, and is followed by a discussion of access to services and the functioning of key programme subsystems. The next section addresses the quality of service received by clients, and the report concludes by making a comparison of the current findings for the national programme with those of the first study to assess the degree and types of changes over the six year period since 1989.

7 Division of Family Health, Logistics Management Unit, Kenya Ministry of Health Database of Government of Kenya (GOK) facilities offering family planning services, GOK health facilities not offering family planning services and NGO/private health facilities offering family planning services, Division of Family Health, Nairobi, 1994.

8 See Phillips, J., G. Lewis and D. Kabira, Community based distribution program in Kenya, Report to USAID/Kenya, The Population Council, Nairobi, 1993; and Mundy, J. and I. Askew, Current experiences with community-based distribution of family planning in Kenya: a review prepared for USAID/Kenya, The Population Council, Nairobi, 1994.

9 Miller, R., L. Ndhlovu, M. Gachara, and A. Fisher, The situation analysis study of the family planning programme in Kenya, Studies in Family Planning, 22(3):131-143.

10 Mensch, B., R. Miller, A. Fisher, J. Mwita, N. Keyonzo, F. Mohamed Ali, and C. Ndeti, Family Planning in Nairobi: A Situation Analysis of the City Commission Clinics, International Family Planning Perspectives, 20(2): 48-54, June, 1994. 


\section{STUDY METHODOLOGY}

\section{A. OBJECTIVES}

\section{Ultimate objective}

The ultimate objective of this study was to assist the MOH, NCPD, NGOs and donor agencies to plan the expansion and improvement of family planning and other reproductive health services provided in Kenya.

\section{Immediate objectives}

The Population Council conducted a Situation Analysis study of the national family planning and reproductive health programmes of the Ministry of Health, the Nairobi City Council, and several NGO agencies. The results of the study describe the functional capacity, quality of care provided and received, and programme performance at 254 clinical health facilities. The study sought to:
\# identify the strengths and weaknesses of family planning and reproductive health services of several different agencies in Kenya;
\# assess efforts by these agencies to expand and improve services over the past five years; provide information to assist policy and programme decision-making for all collaborating agencies participating in the study;
\# develop indicators for monitoring programme performance in relation to service quality and subsystem functioning.

\section{B. SAMPLING CLINICAL HEALTH FACILITIES}

The health facility was the primary sampling unit for this study. A study undertaken previously had shown that there appear to be different levels of quality between services provided by Government and NGO facilities. ${ }^{11}$ There was a need, therefore, to stratify the sample of facilities visited initially according to these two sectors. Stratification by province was then undertaken to ensure national representation. Finally the sample was also stratified according to type of facility (i.e. hospital, health centre and dispensary) because each type provides different levels of services. A sample of 219 health facilities was randomly selected from the $\mathrm{MOH}$ facility database ${ }^{12}$ according to these strata (the sampling plan is described in detail in Appendix 1).

11 Ndhlovu, Lewis, "Quality of Care in Family Planning Service Delivery in Kenya: Clients' and Providers' Perspectives", The Population Council, Nairobi, Kenya, 1995. 
Some additional facilities were deliberately included in the study at the request of the Nairobi City Council (NCC), Pathfinder International, AVSCI, the Family Planning Association of Kenya (FPAK) and Marie Stopes International, so that more detail could be obtained regarding these particular programmes. Thus, all 44 NCC clinics, three Marie Stopes and two FPAK facilities were also included in the sample in addition to the randomly selected facilities to give a total sample size of 254 facilities. The distribution of facilities by the two key strata, type of facility and sector, is given on Table 1.

Table 1: Sample sizes by facility type of sector

\begin{tabular}{||c|c|c|c|c||}
\hline & Total & Government & NGO & NCC \\
\hline Dispensary & 71 & 53 & 17 & 1 \\
\hline Health Centre & 120 & 49 & 28 & 43 \\
\hline Hospital & 63 & 45 & 18 & 0 \\
\hline Total & 254 & 147 & 63 & 44 \\
\hline
\end{tabular}

It should be noted that the "NGO" sector includes facilities supported by CHAK, FPAK, Marie Stopes International, some quasi-governmental clinics and a few private clinics. The "dispensary" group for the NGO sector includes some maternities that provide family planning services as well as some small clinics that do not qualify as health centres.

\section{DATA COLLECTION}

The Situation Analysis approach is designed so that at each of the 254 health facilities visited, information is collected through observations, interviews and an inventory. Five data collection instruments are needed; the standard instruments were customized for application in Kenya during two planning workshops held in October, 1994 and January, 1995. The five instruments are:

\# Inventory for Facilities Available and Services Provided at the Service Delivery Point

\# Interview Schedule for Staff Providing Family Planning and MCH Services at the Service Delivery Point

\# Observation Guide for an Interaction between Consenting Family Planning Clients and Service Providers

\# Exit Interview for Interaction Between Consenting Family Planning Clients and Service Provider

\# Questionnaire for Female MCH Clients Attending the Service Delivery Point. 
Data collected through the inventory and the staff interview provides information on the availability of services, on client load, and, together with the staff interview, on the following programme subsystems through which family planning and other reproductive health services are provided:
1. Logistics/supplies
2. Facilities/equipment
3. Staffing/training
4. Supervision/management
5. IEC materials and activities
6. Record keeping and reporting.

These data, when aggregated across all facilities visited, give a measure of the level of readiness at the national programme level for services to be provided.

Data collected through the observation guide and exit interview for family planning clients describe the quality of service received by the client. The measures of quality have been developed to follow the framework generally used to describe quality of care in family planning programmes ${ }^{13}$ :
1. Interpersonal relations
2. Choice of methods
3. Client-provider information exchange
4. Technical competence
5. Mechanisms to encourage continuity and follow-up
6. Constellation of services offered.

The field visits required careful organization in order for all facilities in the sample to be visited. Ten teams were used, each consisting of three persons -- a nurse midwife, and two interviewers. A senior member of each team was designated as a supervisor. Each team visited a cluster of facilities that were relatively close to each other, and spent approximately six weeks in the field visiting one facility each day. During every visit, one team member interviewed all clinic staff providing family planning services and completed the inventory instrument. The other two members of the team observed and interviewed all or some of the family planning and $\mathrm{MCH}$ clients attending the clinic on that day. All observations were done by experienced nurse-midwifes. Training was conducted over twelve days (19th April to 3rd May, 1995) immediately prior to the fieldwork. Data collection was conducted from 8th May to 16th June 1995. Data entry, using the Epi Info software, commenced as soon as field work was complete. Data analysis used the statistical software SPSS.

13 Bruce, Judith, "Fundamental Elements of the Quality of Care: A Simple Framework," Studies in

Family Planning, 21:2, 1990; S. Kumar, A. Jain \& J. Bruce. Assessing the Quality of Family Planning Services in Developing Countries. Programs Division Working Papers No. 2, The Population Council, New York, 1989. 
A Data Interpretation workshop was held in September 1995 at which the preliminary results were presented to key programme managers for their review and interpretation. The results were then compiled according to the suggestions made during this workshop and presented at a national seminar drawing over 70 participants from the Government, the NGOs, donor communities and researchers in March 1996. Suggestions and recommendations from these two meetings have been used to guide further analysis and to finalizing this report.

\section{SAMPLE CHARACTERISTICS}

At the 254 facilities included in the sample, data were collected from:

- interviews with 562 providers

- observations of 958 family planning clients

- 241 new clients

- 717 revisit clients

- $\quad$ exit interviews with 927 family planning clients

- exit interviews with 1,738 $\mathrm{MCH}$ clients.

There were fewer exit interviews than observations of family planning clients because it was not possible to interview 31 clients after they had received their service, usually because they wanted to leave the clinic immediately. Among the "new" family planning clients observed, 170 were completely new users of family planning and 71 were restarting family planning after a break. The majority of the new clients began using the injectable (41 percent), combined pill (20 percent) and progestin-only pill (15 percent), although the IUD, condom, sterilization and Norplant ${ }^{\circledR}$ implant were all observed to be accepted; 15 women decided not to start using a method. Of the revisit clients, the vast majority (661) were coming for resupply or follow-up, and 56 clients came because they had a problem (usually with side effects) or wanted to change / discontinue their method ${ }^{14}$.

For the 1,738 MCH clients interviewed, most were coming for child immunization (45 percent) or for antenatal care (28 percent), but 16 percent came because their child was ill, and the remaining 11 percent came for other reasons.

Table 2 shows selected socio-demographic characteristics of the clients and staff interviewed. The MCH and family planning clients were similar in terms of marital status, religion and educational achievement, although the family planning clients tended to be older and, on average, have one more child than the MCH clients. A far smaller percentage of family planning than $\mathrm{MCH}$ clients wanted to have any more children, suggesting that these clients are more likely to have completed their desired family size. The vast majority of both $\mathrm{MCH}$ and family planning clients wanting another child wanted to wait more than one year.

14 Interestingly, on conclusion of the consultations, 23 clients who had originally come for resupply or follow-up actually ended up stopping or switching methods. 
Table 2: Characteristics of clients and staff interviewed

\begin{tabular}{|c|c|c|c|c|}
\hline \multicolumn{2}{|c|}{ Characteristics } & $\begin{array}{c}\text { MCH } \\
\text { clients } \\
(\mathbf{n}=\mathbf{1 7 3 8})\end{array}$ & $\begin{array}{c}\text { FP } \\
\text { clients } \\
(n=927)\end{array}$ & $\begin{array}{c}\text { Staff } \\
(n=562)\end{array}$ \\
\hline \multicolumn{2}{|c|}{ Mean age (in years) } & 26 & 29 & 37 \\
\hline \multicolumn{2}{|c|}{ Mean number of living children } & 2 & 3 & 3 \\
\hline \multicolumn{2}{|c|}{ Proportion Christian } & 91 & 93 & 97 \\
\hline \multirow[t]{2}{*}{ Marital Status } & $\begin{array}{l}\text { Married (polygamous } \\
\& \text { monogamous) }\end{array}$ & 84 & 82 & 80 \\
\hline & Single & 10 & 8 & 14 \\
\hline \multirow{2}{*}{$\begin{array}{l}\text { Highest level of } \\
\text { Education }\end{array}$} & Primary & 59 & 56 & \\
\hline & Secondary & 29 & 30 & \\
\hline \multicolumn{2}{|c|}{ Desire more children } & 54 & 39 & \\
\hline \multirow{4}{*}{$\begin{array}{l}\text { Timing of next } \\
\text { child }\end{array}$} & Immediately & 5 & 2 & \\
\hline & Wait up to 1 year & 3 & 4 & \\
\hline & Wait more than 1 year & 84 & 91 & \\
\hline & Uncertain & 8 & 3 & \\
\hline
\end{tabular}




\section{KEY FINDINGS AND PROGRAMMATIC RECOMMENDATIONS}

\section{A. ACCESS TO FAMILY PLANNING SERVICES}

Whether a client has easy and convenient access to family planning services, however, depends on several factors, including:

- provision of family planning and other reproductive health services

- facility opening times

- availability of contraceptive methods at the health facility

- cost of services to the client

- travel and waiting time to obtain services

1. Availability of family planning and other reproductive health services at the facilities

Although all facilities visited were identified on the $\mathrm{MOH}$ database as family planning service delivery points, on the day of the research teams' visits, 16 of them (i.e. six percent) were found not to be providing family planning services. For some of the NGO facilities this was because they only provide services on certain days, and in two cases they were Catholic health facilities and so did not provide family planning services at all. Of the seven Government facilities not offering services, most were dispensaries which did not have a staff person trained in family planning on duty.

Over 90 percent of these facilities were also providing antenatal and child welfare services, a little over half (55 percent) provided post-natal care and RTI/STI management, and 21 percent provided HIV/AIDS management services. A clear difference between the three sectors in relation to providing RTI/STI and HIV/AIDS services was found. A much larger proportion of NGO facilities offered RTI/STI (72 percent) and HIV/AIDS (51 percent) services than either the facilities of the Government ( 60 and 19 percent respectively) or the NCC ( 24 and 4 percent respectively).

Moreover, over half of the facilities had no visible sign announcing the availability of family planning services, which means that many women may not even know that they can get family planning at this clinic; indeed, among the $\mathrm{MCH}$ clients interviewed, only 59 percent knew that family planning services were available at the clinic.

\section{Facility opening times}

For most health facilities, the nurse in-charge stated that services are available during the official working hours (8:00 am to 5:00 pm) for five days per week. This was observed to be generally true, although half of the facilities began seeing clients more than one hour (70 minutes on average) after the opening time. Opening hours were felt to be convenient by most (86 percent) family planning and MCH clients. 


\section{Availability of contraceptive methods at the health facility}

Table 3 describes the availability of different contraceptive methods at the facilities visited, both in terms of whether the methods are normally provided and whether they were available on the day of the visit. The vast majority of facilities usually provide oral contraceptives, condoms and the injectable Depo Provera, although for each of these methods, some facilities were out of stock on the day of the visit. The IUD is normally provided in almost three quarters of health facilities, but appears to be unavailable at times - for example, on the day of the visit one quarter of the facilities that provide the IUD were out of stock. Moreover, IUD stockout seems to be a problem across all types of health facilities, and is more common amongst the NGO clinics than the Government or NCC facilities. Other methods which appear to have stockout problems are spermicides, Noristerat injectables, and, to a lesser extent, the Norplant ${ }^{\circledR}$ implant. At the time of the study, however, both spermicides and implants were suffering from a supply problem at the central level and so this problem may be exaggerated for these methods. Though stockouts for these methods seem to be equally problematic across all types of facilities, the majority of facilities with stockout problems are located in the rural areas.

Table 3: Percent of facilities usually providing a method and method stockouts

\begin{tabular}{||l|c|c||}
\hline \multicolumn{1}{|c|}{ Method } & $\begin{array}{c}\text { \% of facilities usually } \\
\text { providing method }\end{array}$ & $\begin{array}{c}\text { \% of facilities providing } \\
\text { method with stockout on } \\
\text { day of visit }\end{array}$ \\
\hline Combined Oral Contraceptive & 98 & 4 \\
\hline Progestin-only Pill & 94 & 16 \\
\hline Condom & 98 & 8 \\
\hline IUD & 74 & 96 \\
\hline Injectable - Depo Provera & 95 & 40 \\
\hline Injectable - Noristerat & 68 & 100 \\
\hline Diaphragm & 3 & 99 \\
\hline Spermicides & 43 & 22 \\
\hline Implant - Norplant & 12 & N/A \\
\hline Female Sterilization & 23 & N/A \\
\hline Vasectomy & 12 & 98 \\
\hline Natural Family Planning & 18 & 96 \\
\hline \hline
\end{tabular}

The mean number of methods usually provided at all the health facilities (regardless of type or sector) was approximately six. However, when the methods actually available at the facility on the day of the visit are considered, the mean number of methods available is four 
- suggesting that, on average, clients have a choice of approximately four methods (most likely to be oral contraceptives, condoms, injectables and IUDs).

\section{Cost of services to the client}

Family planning services in Kenya are free in the public sector, and so the vast majority of clients (over 80 percent) reported that they did not pay anything for the consultation, medicines or registration. Cost of travel, for those who did not walk, was on average five Kenya shillings (a short trip on a matatu). For the one fifth of all clients who did have to pay something for supplies, registration / consultation or medicines, both in Government and NGO clinics, the total cost of services was acceptable to a higher percentage of family planning clients ( 84 percent) than $\mathrm{MCH}$ clients (72 percent), probably because the $\mathrm{MCH}$ clients were more likely to have paid for medicines, etc. When asked how much they paid, the amounts were, on average quite low, coming to about seven Kshs for family planning clients and ten Kshs for MCH clients.

\section{Travel and waiting times}

The $\mathrm{MCH}$ and family planning clients appear to travel similar distances, as both groups estimated that it took them, on average, three-quarters of an hour to get to the facility; the majority (75 percent) walked to the facility. When asked to estimate how long they had to wait to be served, a difference was found in that the $\mathrm{MCH}$ clients reported waiting, on average, threequarters of an hour, whereas the family planning clients reported waiting for approximately one hour. For both groups, however, most women ( 69 percent) felt that their waiting time was reasonable.

More than one third of family planning clients said that they knew of another place near to their home where they could get family planning services, thus indicating that many women in Kenya have a choice of method source. When asked why they did not use the other source, the most frequently cited reasons were poorer quality services and higher costs.

\section{Recommendations for improving access to services}

1) Facility managers should clearly publicize all services available at the facility through better use of signs.

2) Facility managers need to review and revise the scheduling of daily activities at their facilities so that they start and finish closer to official opening hours. At the busier clinics this should include encouraging clients (and providers) to attend for service delivery throughout the day to reduce congestion in the morning.

3) Although most facilities regularly provide at least four contraceptive methods and stockouts for these methods are not too much of a problem, efforts could be made to broaden the range of methods available by increasing the provision of natural family planning and, in certain facilities, the diaphragm. 
4) Clients currently pay nothing or very little for family planning services. Almost all of those that did pay felt that it the amount was acceptable, which suggests that a costrecovery scheme for family planning could be introduced if carefully planned.

\section{B. VOLUME OF SERVICES PROVIDED AT HEALTH FACILITIES}

\section{Family planning services}

As would be expected, the number of family planning visits made to health facilities varies significantly according to the type of facility, the sector providing the services, and the location of the facilities. Thus, hospitals had, on average, 3,800 visits annually, health centres 1,400 visits, and dispensaries 740 visits. Those facilities administered by the NCC in the densely populated Nairobi urban area had, on average, the most family planning visits $(2,300)$, followed by the Government facilities $(1,400)$, with the NGO facilities having the least (770), although there was much variation within each sector. Further analysis shows that the type of facility and its location in either urban or rural areas greatly influences the volume of family planning visits while the authority managing the health facility is not as important.

As has been found in other Situation Analysis studies, a few facilities tend to serve most of the clients. Thus, about one quarter of the facilities had 62 percent of the total client load for all the facilities visited; as may be expected, two thirds of these facilities are hospitals and the rest are health centres.

\section{Maternal and child health services}

Data for maternal and child health visits were collected from 84 percent of the health facilities that had useable service statistics. Total $\mathrm{MCH}$ figures include child welfare and antenatal care visits, but due to difficulties in obtaining usable statistics for postnatal care visits, these were excluded. The variation of $\mathrm{MCH}$ visits, as with family planning visits, varies according to the type, sector and location of facilities. On average, hospitals receive far higher $\mathrm{MCH}$ visits $(16,500)$ than health centres $(6,700)$ and dispensaries $(3,300)$. Interestingly, the Government sector facilities have, on average, higher volumes of $\mathrm{MCH}$ clients than the NCC sector clinics; this may be due to the fact that the NCC does not have any hospitals. 


\section{FUNCTIONING OF HEALTH FACILITY SUBSYSTEMS}

\section{Physical infrastructure}

The infrastructure of the health facilities was evaluated in terms of the availability of piped water, electricity, waiting rooms and working toilets on the day of the visit. Figure 1 shows that although availability of piped water and electricity is a problem at many health facilities, the overall situation may not be as poor as the data portray. A composite score for the four elements shows that over 60 percent of the health facilities had three or more of these present. In addition, some health facilities in rural areas collect rain water, and although electricity may not be available, gas, solar power systems, and firewood are often used as
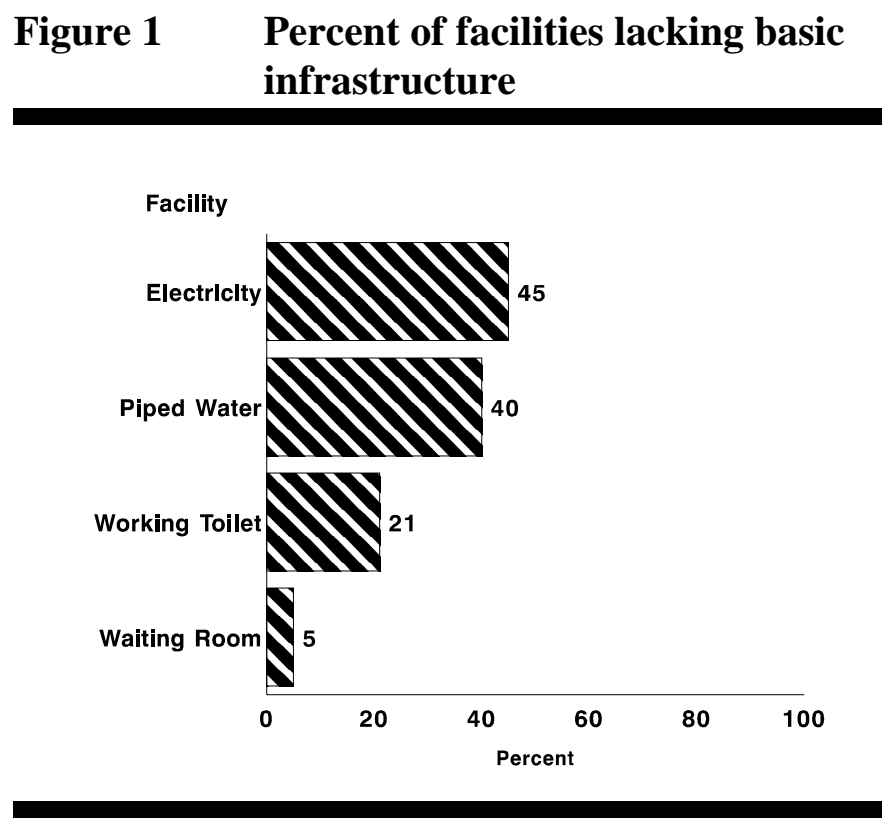
substitutes for heating and refrigeration in rural areas. These elements were more likely to be missing in rural than urban clinics, but one unexpected finding was that the lack of working toilets was more pronounced in urban than rural areas. Most of the 12 facilities without a waiting room were Government dispensaries in rural areas, although three hospitals did not have waiting space available to family planning clients.

\section{Equipment for providing family planning services}

Certain basic equipment are needed for providing family planning services; Table 4 describes what was found at the facilities visited. Overall, most facilities appear to be fairly well equipped, although a few items appear to be problematic, notably a source of lighting for genital examinations ${ }^{15}$. However, at most facilities there is generally sufficient natural light to enable providers to carry out examinations effectively. The MOH service delivery guidelines specify that all health facilities should have, as a minimum, a blood pressure (BP) machine, a weighing machine, gloves (disposable or non-disposable), and a speculum. Only one quarter of the facilities were found to have all these items, although a further 66 percent were only missing one or two items. Two Government health centres were found to have none of these items at all.

Only 16 percent of the facilities were found to be equipped with the full range of sterilizing equipment, sterilizing lotion and gloves, but the vast majority of facilities had at least two of these items. Only ten percent were lacking gloves and nine percent lacked

15 Source of light for examinations is defined as either a torch or angle poise lamp. 
sterilizing equipment, but over one third lacked sterilizing lotion, a problem which appears to be universal for MCH/FP clinics throughout sub-Saharan Africa.

Table 4: Percentage of facilities lacking equipment by sector

\begin{tabular}{|l|c|c|c|c||}
\hline Equipment & $\begin{array}{c}\text { All } \\
\text { facilities }\end{array}$ & $\begin{array}{c}\text { Govt. } \\
\text { facilities }\end{array}$ & $\begin{array}{c}\text { NCC } \\
\text { facilities }\end{array}$ & $\begin{array}{c}\text { NGO } \\
\text { facilities }\end{array}$ \\
\hline BP machines & 16 & 21 & 13 & 5 \\
\hline Adult weighing machine & 10 & 13 & 0 & 8 \\
\hline Light source for exams & 43 & 51 & 39 & 28 \\
\hline Specula & 7 & 7 & 2 & 6 \\
\hline Instrument containers & 18 & 22 & 20 & 16 \\
\hline Tenacula & 16 & 18 & 4 & 18 \\
\hline Scissors & 15 & 22 & 0 & 8 \\
\hline Swab containers & 16 & 15 & 2 & 26 \\
\hline Sterilizing equipment & 9 & 12 & 9 & 10 \\
\hline Sterilizing lotion & 39 & 54 & 8 & 24 \\
\hline Any gloves & 10 & 10 & 7 & 11 \\
\hline Kidney dishes & 5 & 5 & 2 & 6 \\
\hline Stethoscope & 6 & 11 & 0 & 6 \\
\hline Examination couch & & & 11 & 5 \\
\hline
\end{tabular}

Provision of the injectable: The Depo Provera injectable was provided at all but six percent of the facilities, and appears not to suffer from stockouts excessively, and so would appear to be widely available; the Noristerat injectable is being phased out by the MOH. To provide this method requires a clean syringe and needle, however, and the availability of these supplies appears to be somewhat problematic in many facilities. Sometimes the vial of Depo Provera comes pre-packed with a needle and syringe (the $\mathrm{MOH}$ is increasingly trying to obtain this type), although anecdotal evidence suggests that the needle and syringe are sometimes removed and used for other purposes in the clinics. Only one half of the facilities that stocked Depo Provera were found to have both needles and syringes available; just over a third had either needles or syringes, and 16 percent had neither. Given this shortage of basic supplies needed to provide the method, it appears that many providers are resorting to asking clients to purchase and bring with them needles and syringes ${ }^{16}$. 
Provision of the IUD: Figure 2 shows the proportions of the 186 health facilities that normally provide the IUD that were lacking equipment considered important for IUD insertion. Virtually all facilities were missing at least one piece of equipment, the most serious being the one quarter of facilities missing the IUD itself. Even when the IUDs are available at the facility, however, providers are frequently inserting them without the full range of equipment and supplies necessary for a completely safe procedure.
Figure 2 Percent of facilities providing the IUD lacking equipment for insertion $(\mathbf{n}=186)$

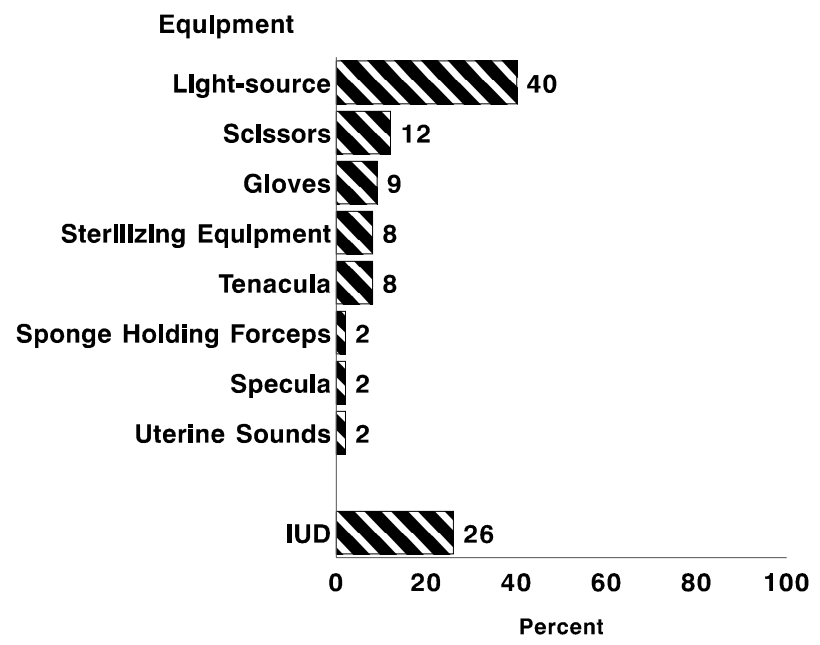

\section{Information, Education and Communication activities}

Providers at Government and NCC health facilities are expected to give group health talks every morning before commencing service delivery. At only 22 percent of Government facilities and 36 percent of NCC facilities were health talks held on the day of visit. Two themes dominated these talks, child welfare and family planning, an observation supported by clients' recollection of the content of the talks; when asked, most women mentioned these two topics. Antenatal care was discussed in only 17 percent of the health talks, and AIDS and RTI/STIs were discussed during only three health talks.

Table 5 shows that most MCH/FP units have at least one poster about family planning and/or child welfare; the percentage of facilities with IEC materials for antenatal and postnatal care was negligible. Not surprisingly, the increasing concern about HIV/AIDS is reflected in the fact that posters on this were found in about two thirds of the health facilities. The "other" category includes anatomical models, calenders, etc. 
Table 5: Percentage of facilities with IEC materials available by type of message

\begin{tabular}{||l|c|c|c|c||}
\hline Service & Posters & $\begin{array}{c}\text { Flip } \\
\text { Chart }\end{array}$ & Brochures & Others \\
\hline Family Planning & 79 & 35 & 38 & 62 \\
\hline Child Welfare & 81 & 14 & 6 & 44 \\
\hline RTI/STD & 22 & 4 & 5 & 17 \\
\hline HIV/AIDS & 64 & 2 & 10 & 33 \\
\hline
\end{tabular}

Clients were asked whether they had ever received any educational materials to take home. Very few clients stated that they had ever taken any educational materials home, although more family planning (16 percent) than $\mathrm{MCH}$ (10 percent) clients had ever done so.

Only one third of MCH clients reported that they had seen or heard anything about family planning during the course of their visit, and this was mostly through seeing a poster (66 percent), although one quarter said that family planning had been discussed with them during their MCH consultation. Clients using the NCC and NGO facilities were more likely than those using the Government facilities to have reported that they had seen family planning posters, pamphlets or contraceptive samples.

There seems to be a significant relationship between the existence of IEC materials and the holding of group talks: those facilities that held group talks on the day of the visit tended also to be those which have IEC materials. For example, health facilities that held group talks have almost double the number of family planning posters than the facilities that did not hold health talks. This seems to be the case regardless of the type of facility, sector or locality. It appears, therefore, that a small group of health facilities do make a concerted effort to educate their clients using a combination of IEC materials and health talks. These health facilities tend to belong to the Government or NCC, and are more likely to be hospitals or health centres.

\section{Supervision}

The Government policy that requires that facilities should receive a supervisory visit at least every three months. When asked how many supervisory visits they had had in the last six months, 62 percent of Government facilities and 71 percent of NCC facilities reported having had at least two visits, suggesting that approximately two thirds of these facilities are being supervised in accordance with MOH policy. Approximately one quarter of Government and NCC facilities had not received any supervisory visits for family planning, $\mathrm{MCH}$ or STI services in this same period, however, which implies that supervision is unevenly undertaken across the programme. 
For those facilities that received supervisory visits, the most frequently mentioned actions taken by supervisors during the visit are shown on Figure 3. It is encouraging to note that the supervisory actions taken during the visits appear to be quite good, with two thirds of supervisors asking about problems, and almost half the supervisors observing several services during one visit. This integrated approach in supervision should be sustained since it minimizes transport and staffing costs. The category of "other" actions includes mostly bringing supplies of commodities to the facility. In addition, almost all health facilities reported that they had developed some mechanism for solving problems that arise in the course of work, the most frequently mentioned being through group (75 percent) and individual meetings (18 percent).

\section{Staff training and experience}

Enrolled Nurses were the predominant category providing family planning services and were found in 97 percent of the facilities; most of these were also trained in RTI/STIs. These were followed by Registered Nurses found in 42 percent of the facilities, but only 17 percent of the facilities had Registered Nurses who were trained in RTI/STIs. Only a small proportion of Clinical Officers, who are the managers of the health facilities, have been trained in family planning and RTI/STIs. Specialists and medical doctors are rarely found at the health centres and dispensaries and generally do not provide family planning even in the hospitals.

\section{Most staff interviewed said that they provided child welfare (90 percent), antenatal (87 percent) and family planning (85 percent) services. A significantly smaller percentage of staff mentioned that they provide RTI/STI (15 percent) and HIV/AIDS (4 percent) services.}

The ability of staff to provide a wide range of services at the health facilities is, to a large extent, determined by the type of basic and

\section{Figure 3 Actions taken by supervisors when visiting facilities $(n=228)$}

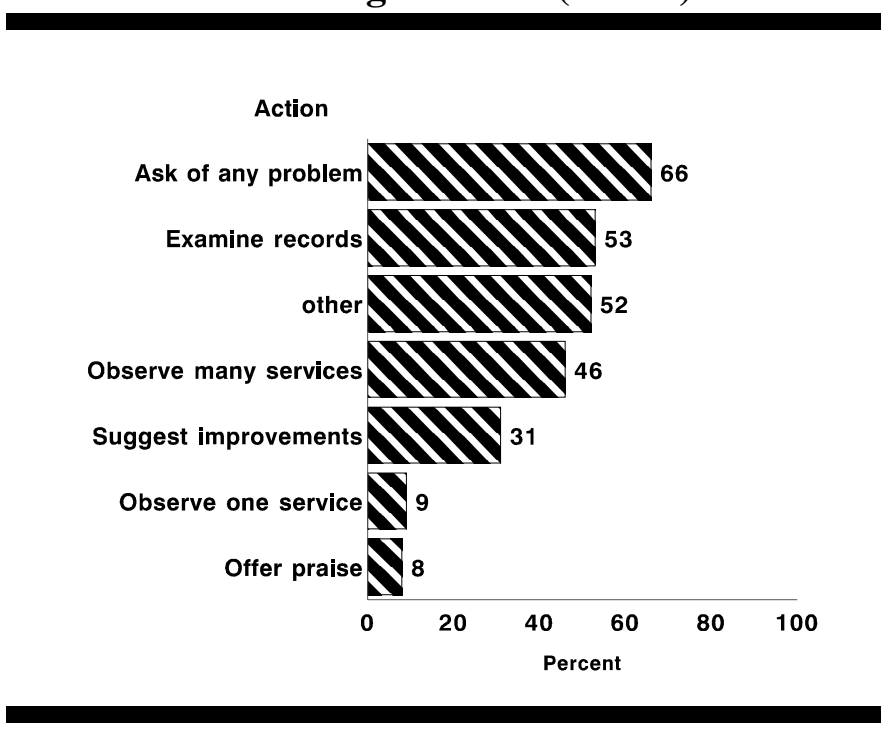

\section{Figure 4 Percent of providers attending post-basic training courses $(n=452)$}

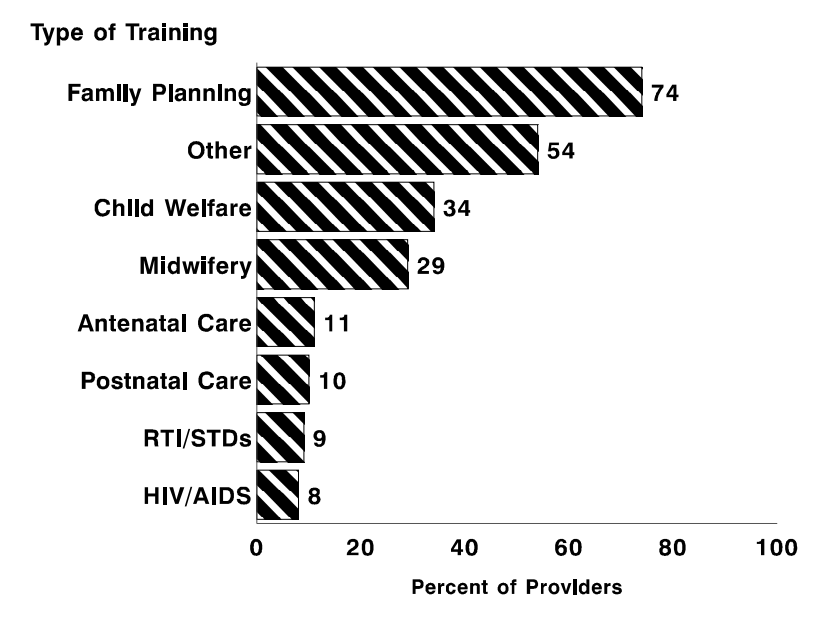


subsequent refresher training that they receive. The staff are generally well experienced and qualified, with an average of four years work experience since their basic training. In addition, 82 percent have had some form of post-basic training (see Figure 4). Significantly, most staff have received post-basic family planning training, and so credit must be given to the intensive efforts of the Government's training programme since 1972. Over half of those attending training courses have been trained in "other" aspects of service delivery, such as management, recordkeeping and logistics. To date, there has been little post-basic training in RTI/STIs and HIV/AIDS, and just less than half the staff reported that RTI/STIs had been part of their basic training. For the current MCH/FP programme to become a more integrated reproductive health programme, therefore, significant attention and resources need to be committed to strengthening staff training in most of the non-family planning reproductive health services, including RTI/STIs, HIV/AIDS, antenatal and postnatal care, and child welfare services.

Of those who had attended post-basic family planning courses, the highest proportion (84 percent) mentioned that they had attended a course on IUD insertion and removal ${ }^{17}$, and three quarters of providers had attended the course on clinical skills in family planning. Just over two thirds of providers expressed satisfaction with the family planning training they had received and rated it adequate for performing their duties.

\section{Commodities management}

Over three quarters of the health facilities had a written inventory for family planning commodities, whereas fewer had inventories for immunization vaccines (73 percent) and RTI/STI (51 percent) drugs. Government facilities were more likely to keep these inventories than the NGO or NCC facilities. In addition, hospitals and dispensaries appear to have better inventory systems than health centres, although there is no obvious reason why this is the case.

It was also observed that more than one third of the facilities had commodities that were not stored according to expiration dates, as is recommended practice; this appears to be due mainly to insufficient storage space at the facility. The substantial proportion of facilities with sufficient storage but improperly organized commodities, however, suggests that in some facilities there is a need to update the staff responsible on correct commodities management.

\section{7. $\quad$ Record keeping and reporting}

17 It is worth noting that about 12 percent of the providers who had been trained in IUD insertion had not provided the service for at least three months before the survey. 
Of the 95 percent of facilities which had client records available, three quarters kept well ordered records; the remaining had records which were partially usable. However, this should not disguise the fact that a quarter of the facilities visited had some missing records. Most health facilities (64 percent) keep different record cards for clients visiting for different services. It should also be noted this means that most facilities are burdened with a large number of registers which they keep for different purposes which may contribute to poor record keeping.

There is an inconsistent pattern of reporting by health facilities; about 70 percent send reports every month while the remainder send their reports every three months. These inconsistencies do not vary by whether the facility is in the public or NGO sector, nor by the type of facility. It is not clear, therefore, whether this is because of a lack of an established policy on reporting frequency, or whether staff are unable to follow existing guidelines. 


\section{Recommendations for improving subsystem functioning}

1) The lack of basic equipment and supplies in some facilities should be addressed by the relevant managing authorities. Recommended standard practices require that all new family planning clients receive a full medical examination (including taking blood pressure, weight and a pelvic examination), and so the availability of gloves, blood pressure and weighing machines should be guaranteed at all facilities.

2) To improve clients' choice of contraceptive methods, all contraceptive commodities for the services being offered, including IUDs, injectables and spermicides, and their supporting supplies and equipment (e.g. needles, syringes, etc) should be made available at all health facilities at all times.

3) Given that many women cite the clinic as the first and main source of family planning information, a concerted effort should be made to undertake daily group talks and discussions for clients (using good quality visual materials to illustrate clear themes), and to include discussions of other relevant services during individual consultations when providing MCH or FP services. Attention could be paid to developing specially tailored and packaged IEC material(together with supporting training) that could be used when giving daily health talks and during individual consultations.

4) Very few family planning and MCH clients receive educational materials to take away, even when they are available. Wherever possible, staff should be encouraged to distribute existing materials to literate clients, and efforts could be made to produce more materials and make them available to providers.

5) Overall the frequency and type of supervision is satisfactory, although the proportion of facilities not receiving any supervisroy visits has not decreased since 1989. Supervisory activity reports should be compiled regularly and fedback to facility staff.

6) For MCH/FP providers to play a role in preventing and managing RTI/STIs and HIV AIDS, a strong effort must be made to develop and provide appropriate post basic training in these services, particularly in relation to risk assessment and screening.

7) Greater efforts need to be made to ensure that commodities are correctly stored.

8) Staff need to be trained in the proper maintenance of client records and in their use for planning purposes. A more integrated approach to maintaining records on different reproductive health services should be developed to reduce the overburdened recording system. 


\section{QUALITY OF CARE}

The quality of care received by clients was assessed through observations of 961 family planning client-provider interactions, exit interviews with 930 family planning and 1,755 $\mathrm{MCH}$ clients, and interviews with 562 staff providing family planning services. Over half of these clients were from $\mathrm{MOH}$ facilities (58 percent), one quarter from NCC facilities, and 16 percent were from NGO facilities.

Findings are presented based on the Bruce-Jain framework of six elements of quality of care: 1) interpersonal relations; 2) choice of methods; 3 ) client-provider information exchange; 4) technical competence; 5) mechanisms to encourage continuity and follow-up; and 6) constellation of services offered. There has been an increasing interest in providing broader reproductive health services that go beyond family planning, and so information is presented to give some impressions of the current state of integration in the Kenyan programme.

\section{Interpersonal relations}

Observers noted that in most cases (89 percent) family planning clients were greeted by the provider in a friendly way. Clients were asked several questions to assess their level of satisfaction with the services received at the facility (Figure 5). The vast majority of both family planning and MCH clients were satisfied overall with their visit, and felt that they received the information and services that they wanted. Family planning clients were more likely than $\mathrm{MCH}$ clients to be satisfied with the level of privacy provided, which may be

\section{Figure 5 Clients' satisfaction with services}

because providers probably make more of an effort to ensure privacy for family

planning services, given its higher sensitivity. There is often a courtesy bias, however, when responding to these types of questions, in part because women do not feel comfortable criticizing the health facility or its $\operatorname{staff}^{18}$. There was little variation in the responses amongst clients at $\mathrm{MOH}, \mathrm{NCC}$ or NGO facilities.

Although most clients felt that the consultation time was satisfactory, more than one fifth of MCH clients and 11 percent of family planning clients felt that it had been too short. Amongst these family planning clients, those coming for revisit were more likely to have

18 The study by Ndhlovu cited earlier collected data on client satisfaction using open-ended questions and group discussions, and found much higher levels of dissatisfaction and several examples of how clients felt they had been poorly treated. 
wanted a longer consultation, suggesting that in some cases resupply clients would have preferred a more in-depth discussion of their method use. Ten percent of family planning clients and seven percent of MCH clients felt that the consultation time was too long. Family planning clients at NCC clinics were more likely to be dissatisfied with the length of consultation time, probably because the client loads are highest at these clinics.

\section{Choice of methods}

Actual choice is affected by many factors; data were collected on the availability of methods at the facilities; the methods discussed with clients; and staff attitudes towards providing certain methods to women with different needs.

Availability of family planning methods: For a client to be able to choose a method, that method must be available at the facility. As noted earlier, almost all facilities provide the combined pill, the progestin only pill, the condom, and injectables (over 94 percent for each method), while three-quarters offer the IUD.

\section{Methods discussed with clients: It is encouraging to note that most new \\ Figure 6 Methods mentioned to new family planning clients $(n=236)$} clients were told about six methods on average, even though, as described earlier, most facilities tended to have only four methods available on site. As Figure 6 indicates, the group of methods most often mentioned are also those that are the most commonly available at facilities. The types of pill mentioned are separated out to emphasise how frequently the progestin-only pill is mentioned, but when taken together 86 percent of clients had any type of pill mentioned to them, that is, it was the most frequently mentioned method.

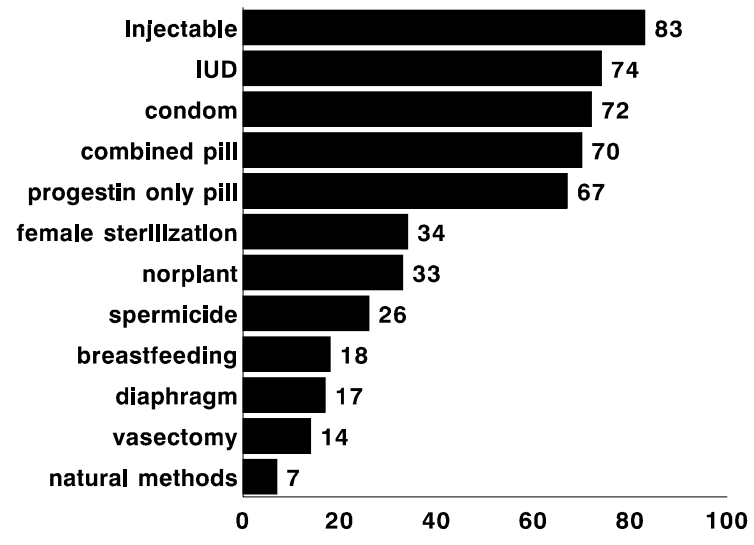

Restrictions on method provision: Even if a method is available at a facility, and a woman is told and knows about this method, it is possible that there are still restrictions that would limit her choice. Some restrictions are necessary for medical reasons, usually contraindications. Others exist due to policy restrictions, providers' personal biases or a combination of both.

Providers were asked whether they restrict the provision of certain methods to women based on her parity or marital status and whether she should obtain spousal consent before using the method. Table 6 shows the restrictions that staff said they would impose for different contraceptives based on these three factors. 
Table 6: Providers' restrictions by method

\begin{tabular}{||l|c|c|c||}
\hline $\begin{array}{c}\text { Contraceptive } \\
\text { method }\end{array}$ & $\begin{array}{c}\text { Percent requiring } \\
\text { at least one child }\end{array}$ & $\begin{array}{c}\text { Percent requiring } \\
\text { marriage }\end{array}$ & $\begin{array}{c}\text { Percent requiring } \\
\text { spousal consent }\end{array}$ \\
\hline Progestin only Pill & 92 & 17 & 10 \\
\hline Combined Pill & 88 & 14 & 8 \\
\hline Condom & 28 & 6 & 41 \\
\hline IUD & 94 & 33 & 21 \\
\hline Injectable & 95 & 20 & 14 \\
\hline Norplant ${ }^{\circledR}$ implant & 94 & 24 & 28 \\
\hline Female Sterilization & 100 & 42 & 71 \\
\hline
\end{tabular}

The most frequently imposed restriction on providing a method is requiring a client to have at least one child. For the injectable, IUD, Norplant ${ }^{\circledR}$ implant and sterilization methods, this practice would suggest that staff are simply following the MOH's current Family Planning Policy Guidelines and Standards for Service Providers ${ }^{19}$, in which parity restrictions are explicitly recommended for these methods. However, these guidelines do not place any parity restrictions on either type of pill or the condom, nor do they place restrictions based on marital status or spousal consent ${ }^{20}$. The findings concerning marital status and spousal consent probably reflect perceptions of the nature of sexual unions and marriage in Kenya. For example, only six percent feel that a client should be married to use the condom, but 41 percent feel that the woman should have her spouse's consent for its use. Similarly, only 42 percent feel that a woman should be married to have a sterilization, but 71 percent feel that spousal consent must be obtained for this method.

Further insights into providers' perceptions and attitudes were obtained when they were asked what methods they would recommend for women in different situations (Table 7). As would be expected, the non-permanent methods were recommended for delaying or spacing births, although only a little over half the providers would recommend the progestin-only pill or the condom for spacing. Why this should be so is not clear; possibly the progestin-only pill is seen as a "stop-gap" method only to be used during breastfeeding, and the condom is seen as a prophylactic rather than a contraceptive, or both methods are seen to be less effective. As expected, female sterilization was strongly recommended for those wanting no more children, while less would recommend vasectomy. The popularity of the injectable generally amongst providers in Kenya is reinforced here, as it is the most recommended method for spacing and is the third most recommended method for those wanting no more children, scoring much more favourably than the IUD as a long-term method. Only about one fifth of those interviewed said

19 Family Planning Policy Guidelines and Standards for Service Providers. The Family Planning Programme, Division of Family Health, Ministry of Health, Government of Kenya. 1991.

20 It is understood that the $\mathrm{MOH}$ is in the process of revising these guidelines and the recommendation of these three types restrictions are being reconsidered. 
that there was one or more methods which they would never recommend at all, with most opposition being to NFP and the two sterilization methods. The NFP method is clearly not favoured amongst Kenyan providers, as it is also not recommended very highly for spacing either.

Table 7: Provider recommendations for clients with different needs

\begin{tabular}{||l|c|c|c|c||}
\hline \multicolumn{1}{|c|}{ Method } & $\begin{array}{c}\text { Percent } \\
\text { recommending } \\
\text { method for } \\
\text { delaying or } \\
\text { spacing } \\
\text { (n=438) }\end{array}$ & $\begin{array}{c}\text { Percent } \\
\text { recommending } \\
\text { method for } \\
\text { wanting no more } \\
\text { children } \\
\text { (n=439) }\end{array}$ & $\begin{array}{c}\text { Percent not } \\
\text { recommending } \\
\text { method for } \\
\text { client with } \\
\text { RT/STD } \\
\text { (n=434) }\end{array}$ & $\begin{array}{c}\text { Percent } \\
\text { never } \\
\text { recommending a } \\
\text { method } \\
\text { (n=89) }\end{array}$ \\
\hline Combined pill & 83 & 4 & 10 & 14 \\
\hline Progestin only pill & 55 & 2 & 7 & 10 \\
\hline Condom & 50 & 1 & 4 & 10 \\
\hline Female Sterilization & 3 & 98 & 4 & 19 \\
\hline Vasectomy & 2 & 58 & 3 & 16 \\
\hline IUD & 79 & 9 & 92 & 10 \\
\hline Injectable & 84 & 25 & 8 & 11 \\
\hline NFP & 28 & 1 & 3 & 24 \\
\hline
\end{tabular}

\section{Information exchanged between clients and providers}

A family planning service provider is expected to both gather information from clients, as well as impart essential information to clients. Given the increasing emphasis on seeking ways to integrate other reproductive health services into the provision of family planning, this element of service quality will be described in terms of the information exchanged between clients and providers for both family planning and other reproductive health issues, especially RTI/STIs, including HIV/AIDS.

Questions to assess clients' needs: Most new clients were asked their reproductive intentions, i.e. whether they want to space or limit births (79 percent), and the age of their youngest child ( 87 percent). However, less than one half were asked about the total number of children they wanted. Clients attending the NCC clinics were consistently more likely to be asked these questions and clients at the MOH facilities the least likely.

In three-quarters of the consultations, clients were asked about their knowledge of and experience with family planning. Either a client was asked directly by the provider or she mentioned spontaneously herself, that she had a preference for a particular method in almost two thirds of the interactions. Partner communication can and should play an important role in contraceptive decisionmaking and use, but whether a client had discussed family planning with her partner was asked in only a little over half of the interactions. 
There are many questions that a provider can ask to assess a client's risk of either contracting or currently having an STI. As Figure 7 shows, apart from asking one third of new clients about the nature of their sexual relations, most were seldom asked any risk assessment questions about the number of sexual partners in the last year or whether they have history of or concerns about STIs. For revisit clients these questions were even more infrequent; for example, only three percent were asked if they had had any new sexual partners since their last visit.

To determine whether a client might currently have an STI, a provider should ask clients about signs and symptoms that might indicate the presence of an STI, even though many STIs are actually symptomatic. As Figure 8 shows, while one quarter of new clients were asked about abnormal vaginal bleeding, fewer were asked about pelvic pain, abnormal vaginal discharge or genital itching. Again, much fewer revisit clients were asked any of these questions.

Clients attending the NCC clinics were much more likely to be asked these risk assessment and screening questions for STIs than those attending either the MOH or NGO facilities. For example, the nature of sexual relations was asked of 56 percent of new clients at NCC facilities, while it was only discussed with 32 percent and 28 percent of NGO and $\mathrm{MOH}$ clients respectively. Likewise, in asking about possible STI symptoms, new clients at NCC clinics were twice to four times more likely to be asked about vaginal bleeding, pelvic pain and vaginal discharge, and over five times as likely to be asked about genital itching, compared with new clients at $\mathrm{MOH}$ and NGO facilities.
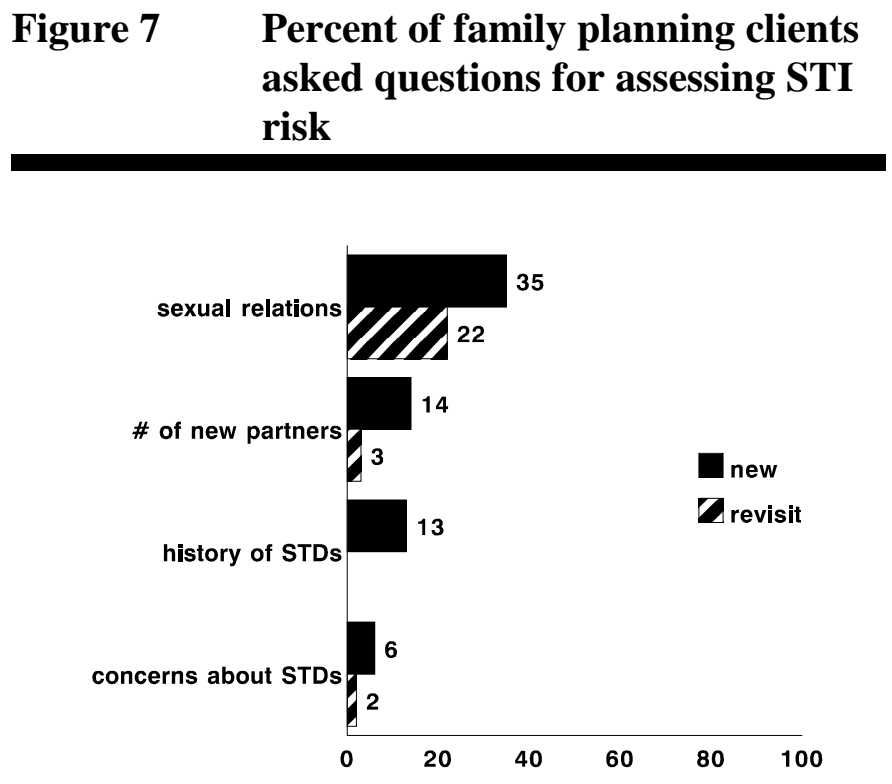

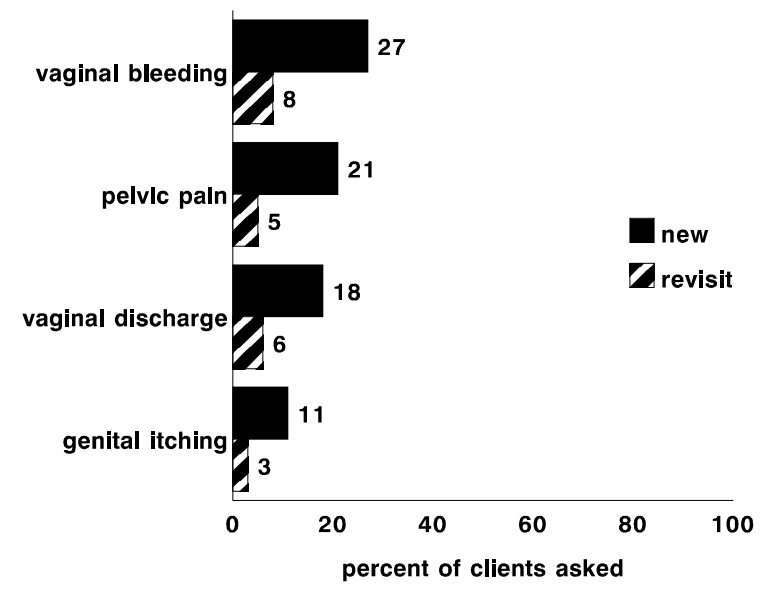


Even if a provider does not obtain detailed information about a client's risk status, the family planning consultation provides a good opportunity to at least inform clients of the importance of using condoms to protect against STIs and HIV. However, in only 12 percent of consultations with new family planning clients were they explicitly told that condoms can protect against STIs, while only one percent of revisit clients were given this information.

Information on method chosen: As Figure 9 shows, in most cases, the provider explained to the new client how to use the selected method. The Figure 9 also shows, however, that in about one third of the consultations observed, the provider did NOT talk about either the method's advantages, disadvantages, side effects or what to do if the woman has a problem with the method. This incomplete information could lead to higher discontinuation rates, as many women are not properly informed about the side effects that they should expect or that they could switch method if they have a problem.
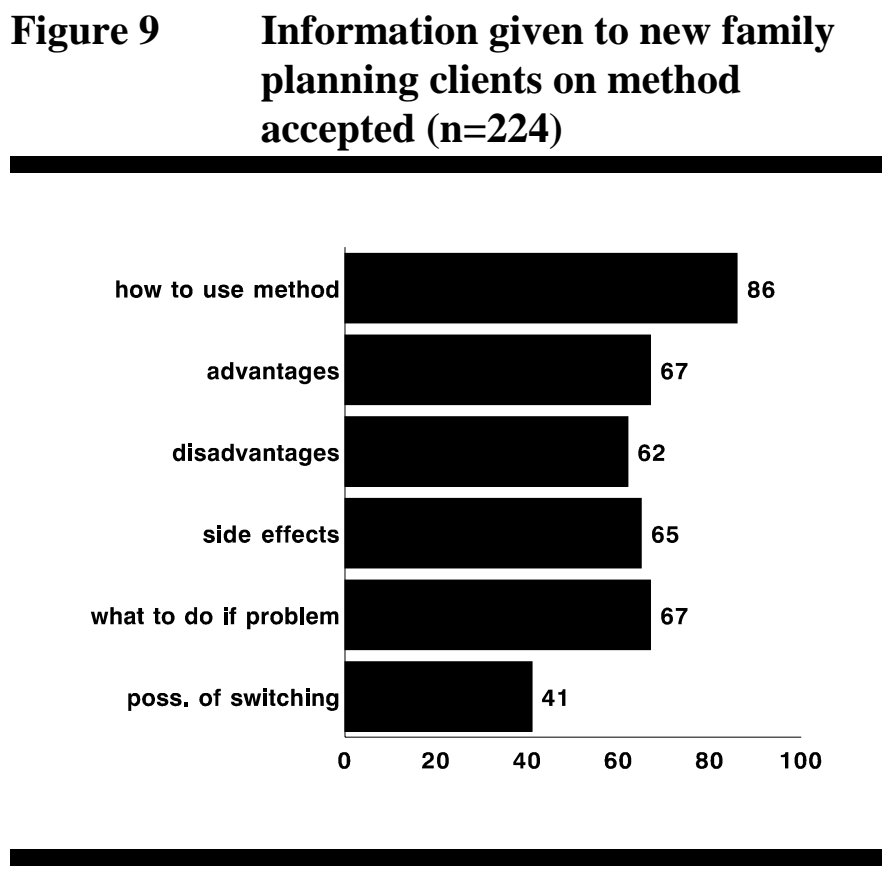

To assess the knowledge clients had about side effects of the contraceptives they were using, they were asked to name the possible problems associated with the method they were using. In general, knowledge was fairly low; over a quarter of pill users could not name any method side effects; the most commonly mentioned problems were nausea, mild headaches and spotting/bleeding. Injectable users were slightly more knowledgeable, but 17 percent could not name any problems; irregular bleeding, amenorrhea and mild headaches were the most commonly mentioned side effects. These data suggest the need to improve the information given to clients about side effects.

In general, revisit clients are given very little information. Moreover, the median length of time a provider spends with a new client ${ }^{21}$ (30 minutes) is three times that of a revisit client (10 minutes). Although revisit clients need less detailed information on family planning than a new client, they are probably equally at risk for STIs, and so would benefit from receiving a risk assessment and screening.

21 The contact time tends to be much longer in a hospital than in a health centre or dispensary. 
Use of IEC materials: Apart from showing clients samples of contraceptives, this seems to be an underutilized method of information exchange, particularly with revisit family planning clients (Figure 10). As most revisit clients are coming for resupply, however, it is not surprising that IEC materials are less often used with them. As was seen earlier, materials such as flipcharts and brochures are not available in many facilities which would explain why they are used infrequently. Use of IEC materials does vary amongst $\mathrm{MOH}$, NCC and NGO clinics: flipcharts were more frequently used in NGO facilities (with 31 percent of new clients) as compared to $\mathrm{MOH}$ and $\mathrm{NCC}$ facilities (10 percent for both), while anatomical models were more commonly shown to new clients in NCC clinics (39 percent) than they were with MOH (22 percent) or NGO (19 percent) clients. This could reflect different availability of materials amongst the different sectors, or a different emphasis in training or procedures at the facilities.

\section{Clinical procedures performed}

Most new and revisit clients had their weight and blood pressure taken, while a substantial proportion of new clients had breast and pelvic examinations (Figure 11). Hardly any clients were given a pap smear, probably because of the lack of facilities for doing so. There was little variation amongst $\mathrm{MOH}, \mathrm{NCC}$ and NGO clients in terms of taking blood pressure or performing a pelvic examination; however, NCC clients were much more like to have their weight taken and be given a breast exam. Although these results suggest a lack of attention to revisit clients, whether they need to have any or all of these examinations is debatable unless it has been a long time since they previously had the exam.

\section{Figure 10 Use of IEC materials with family planning clients}

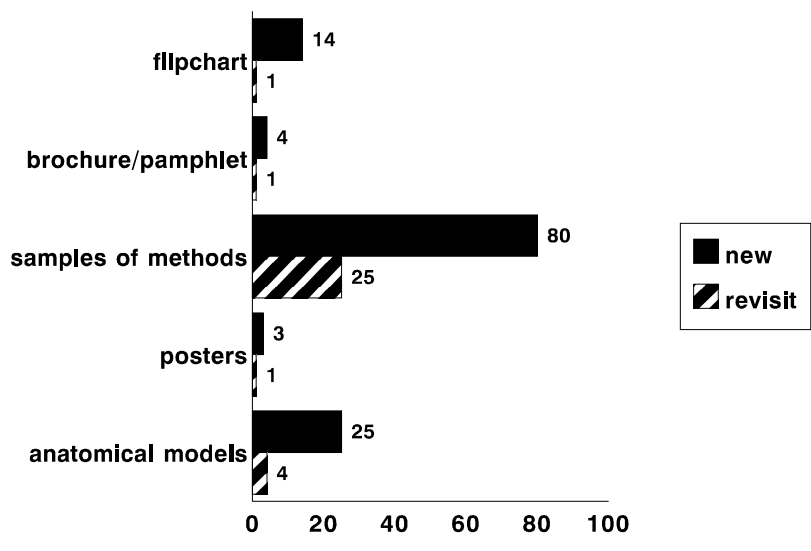

\section{Figure 11 Clinical procedures performed for family planning clients}

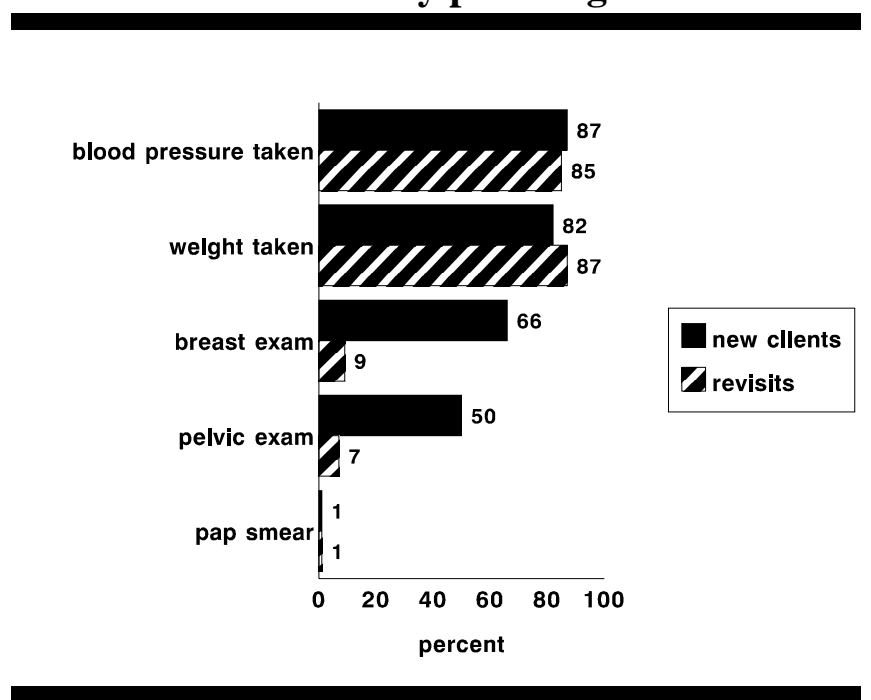


In addition to observing the procedures followed, providers were asked which procedures they felt they should perform prior to offering the combined and progestin-only pills, the injectable and the IUD to new clients. More than three-quarters recommended doing a general medical examination, blood pressure, a pelvic exam and checking weight, and about two-thirds recommended taking a medical history and doing a breast exam. Together, these results suggest that providers know which clinical procedures they should be following in providing family planning methods and, for the most part, actually do follow them. The notable exception is that only eight percent thought it necessary to screen new IUD clients for RTI/STIs, which is surprising given that 62 percent of providers had attended training in IUD insertion and removal, which should have included the importance of this procedure for IUD clients.

A total of 172 pelvic examinations were observed; 120 with new clients and 52 with revisit clients. The type of method accepted by the client did not seem to be associated with whether she had an exam or not. As indicated in Figure 12, most providers followed appropriate procedures when performing these pelvic examinations. Although for one quarter of the examinations a the providers did not wash their hands before the examination, the majority of these providers did wear gloves (only six did not wash hands or wear gloves).

\section{Figure 12 Procedures followed by providers during pelvic exams}

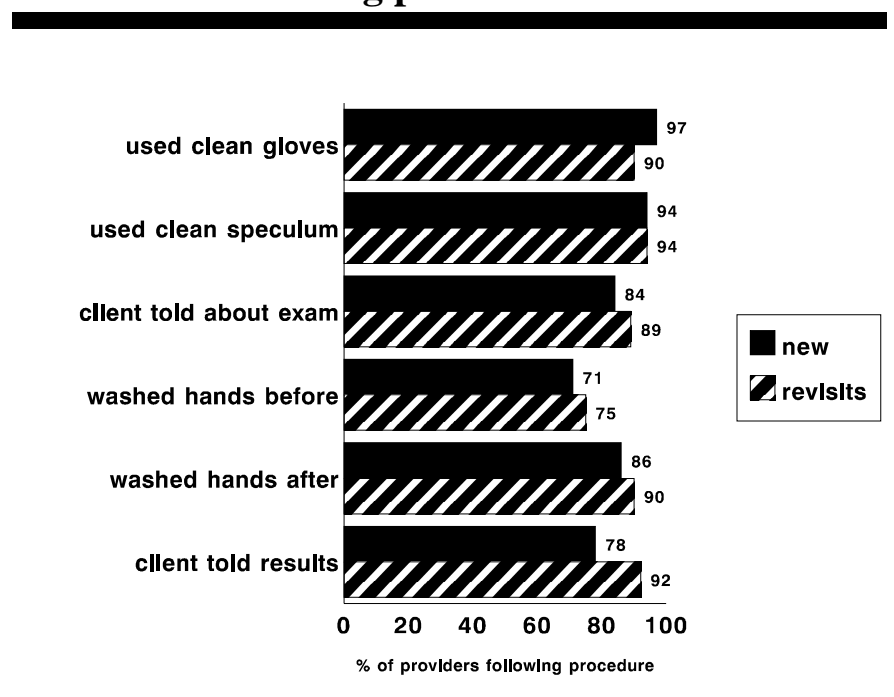

\section{Mechanisms to encourage continuity and follow-up}

In general, providers seem to be doing well on this element - almost all family planning clients (98 percent) were told when to return for resupply or follow-up. In addition, over 90 percent were given a written reminder of when to return.

\section{Constellation of services offered}

During almost half (47 percent) of the consultations with new family planning clients, there was some discussion of at least one other health issue, and even with revisit clients one third discussed one or more health issues. This is a very encouraging result given the move towards a more integrated service delivery programme. There was some variation across sectors, however, with the NCC clinics performing better than the NGO and Government sectors. For example, three-quarters of the new clients and half the revisit clients at the NCC clinics discussing other health issues; clients at the NCC clinics were also more likely to discuss more than just one issue, with the majority discussing two to four issues. 
Figure 13 shows that, amongst those with whom another health issue was discussed, STIs were discussed with one quarter of new clients, and HIV/AIDS was mentioned with 11 percent. Child health was discussed with almost one fifth of new clients, but with only six percent of revisits.

The prevalence of STIs is quite high among antenatal clients in Kenya, but for $\mathrm{MCH} / \mathrm{FP}$ clients to know that they have an STI and to seek treatment they must know about STIs and be able to recognize the key symptoms. Almost all clients had heard of HIV/AIDS, but gonorrhea and syphilis were the only other STIs that a significant number could name. Whether someone knows the names of the different STIs is not as important, however, as being able to identify signs and symptoms that could indicate the presence of an STI so that appropriate treatment can be sought. It is encouraging to see that almost all clients (93 percent) could name at least one symptom suggestive of an STI but, as Figure 14 shows, most could name only one or two symptoms.
Figure 13 Other health issues discussed with family planning clients

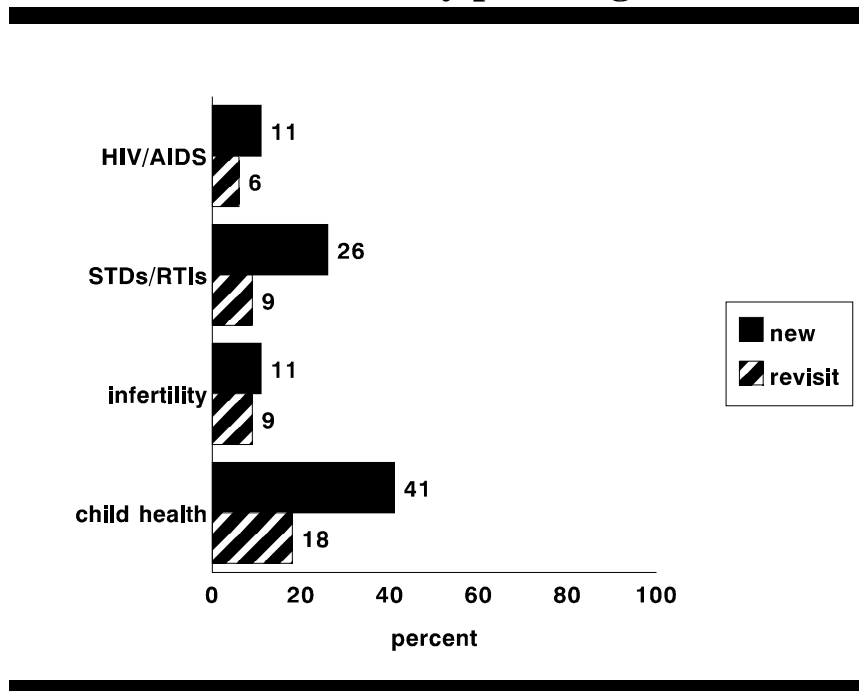

\section{Figure $14 \quad$ FP and MCH clients' knowledge of STI symptoms}

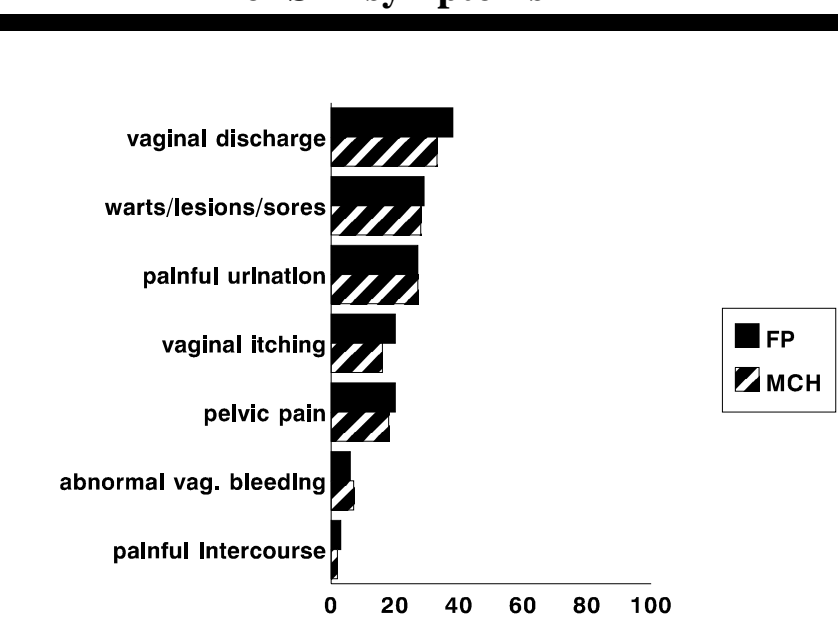




\section{Recommendations to strengthen the quality of care provided}

1) While clients express high levels of satisfaction with the service received, observations by the researchers and findings from a previous research study suggest that the interpersonal skills of some providers could be improved. For some clients, especially a significant proportion of revisit clients, the time spent with the provider was insufficient, and so providers should ensure that clients are given enough time to discuss all their concerns.

2) Influenced by the currently available policy guidelines, the vast majority of providers impose a requirement that a woman must have at least one child before she can use any form of contraception, and substantial proportions require that a woman be married and have spousal consent. It is understood that the guidelines are being revised to remove references to these restrictions, but it is essential that all providers are well informed that such requirements are unnecessary barriers to using contraception.

3) The role of the IUD as a long-term method needs to be reinforced as many providers do not recommend its use for this purpose.

4) In assessing a client's needs, providers must pay more attention to asking questions that assess the client's risk of infection and screen for possible symptoms.

5) In many counselling sessions women are not being informed about the side effects of the method they have accepted or about how to manage them. This aspect of counselling needs to be strengthened when training staff and during routine supervision.

6) Only two-thirds of new clients were given a breast examination; given that this is a lowcost intervention that can be easily used to screen for a possible cancer, the importance and correct way to undertake breast exams should be reinforced during staff training and supervision.

7) In all clinics generally, and in the NCC clinics in particular, there is an encouraging trend towards increased discussion of other topics during the consultation. This trend should be promoted and strengthened, through encouraging staff to pro-actively ask clients about other reproductive health topics, especially STIs, HIV/AIDS, breastfeeding and other child health issues. Some staff may require update training in some of these topics. 


\section{A COMPARISON OF THE MOH FAMILY PLANNING PROGRAMME IN 1989 AND 1995}

\section{A. BACKGROUND}

Kenya was the first country in the world in which a Situation Analysis study was undertaken (in 1989), and is also the first country to have had a second study undertaken. These two studies provide, therefore, a unique opportunity to look at what has happened to the functioning and quality of family planning services at the facility level over this time period.

A number of methodological changes have been made for the 1995 study compared with the 1989 study. Firstly, a larger sample of health facilities was included. The sample was increased from $99 \mathrm{MOH}$ facilities in 1989, to 254 facilities from several organizations in 1995, with approximately 29 percent of the 1995 sample being drawn from the NGO sector, and all 46 NCC health facilities included in the sample. This sampling plan was made to allow for a comparison of findings between the 1991 NCC Situation Analysis Study and those from this 1995 study (this comparison is reported separately).

Secondly, the 1995 Situation Analysis Study collected more information about health facilities, staff providers and clients compared to the earlier study. Thus, in addition to family planning, data were collected on broader reproductive health issues such as sexually transmitted diseases, abortion, female circumcision and adolescent sexuality. Finally, a subsample of health facilities are being revisited for a week rather than one day to collect more detailed information on service quality.

\section{B. SUMMARY OF FINDINGS FROM THE 1989 STUDY}

The 1989 study revealed several inadequacies in subsystem functioning. Supplies of contraceptives were generally available but supervision was scarce, as were health talks which included family planning and educational materials to be used in client education/counseling. Serious weaknesses were also discovered in the in-service training programme for nurses and other personnel. Equipment was frequently absent or not functioning and there were substantial missed opportunities for referral from maternal child health services to family planning. Indeed, while the programmes were generally considered integrated, relatively few $\mathrm{MCH}$ clients received family planning counseling or services on their visit to the SDP. Similarly, relatively few family planning clients received advice, information, or services on other health issues during their visit.

Quality of care was thought to be moderate to moderately high in the national programme, although there was recognition that the data used to draw this conclusion was positively biased. Clients were greeted well and treated reasonably by providers. Choice of methods was provided in the programme - 94 percent of clients observed were provided with information about a number of temporary family planning methods (mean number of methods was 3.8). However, information on side-effects and the management of side-effects was observed to be inadequate in 60 and 44 percent of provider-client interactions, respectively. Waiting times were generally long. Providers did not usually inquire about reproductive goals of clients. Thus providers did 
not obtain important background information for facilitating a match between clients' objectives in using family planning and specific methods. The study also found that about one quarter of the facilities served about 75 percent of all family planning clients; later this same pattern was discovered in Zimbabwe, Nigeria, Tanzania, and Ghana, and is now generally considered representative of a general pattern of facility utilization throughout Africa. ${ }^{22}$

The results of this Situation Analysis study were utilized by a variety of organizations to improve programming in Kenya. ${ }^{23}$ For example, programme managers were brought together to discuss the results and develop administrative plans for tackling some of the problems. The NCPD, the $\mathrm{MOH}$, Nairobi University, and The Population Council collaborated on the development and implementation of OR studies to experiment with possible solutions to some of the quality of care issues identified. ${ }^{24}$ The NCC immediately took clinical equipment stored in their warehouse and supplied it to clinics where it was lacking, and transferred personnel to better reflect the actual case loads of each of its clinics. The NCC also worked collaboratively to re-orient the technical assistance programme being planned with Pathfinder International to better reflect the needs discovered in the study.

\section{COMPARISON OF THE 1989 AND 1995 SITUATIONS}

For the purpose of this comparison only data relating to $\mathrm{MOH}$ facilities will be used because these are the only data that are available from both studies - data from all 99 MOH facilities from the 1989 study will be compared with the sample of $147 \mathrm{MOH}$ facilities that were randomly selected for the 1995 study. The same sampling scheme (stratified by region) was used in both studies, so these two samples are reasonably comparable. During the 1989 study only new family planning clients were observed, whereas the 1995 study observed new and revisit clients; for this analysis, only observations of new clients at $\mathrm{MOH}$ clinics have been included from the 1995 data.

\section{Subsystem functioning}

a) Method Availability: The logistics system as a whole was judged "low-moderate" in 1989 with adequate supplies ${ }^{25}$ of oral contraceptives and Depo Provera in many facilities, but with adequate supplies of condoms, foam, and IUDs available in less than half the facilities.

22 Fisher, A., Family planning in Africa: A summary of recent results from operations research studies, in Conference proceedings and papers, Africa OR/TA Project, Nairobi, 4 -7 October 1993, 64 -82.

23 For further discussion on the utilization of Situation Analysis study findings, see Africa OR/TA Project, Report from panel discussion on the use of situation analysis findings to improve programmes, in Ibid., 103-108.

24 The Population Council, "Integrated Approach to Operations Research for Strengthening the MOH Family Planning Program in Kenya: Workshop on Research Results and Implications for Collaborative action." Serena Hotel, Nairobi, 1992.

25 "Adequate supplies" are defined as two or more months of supply on hand, given the clinic's client load for each method. 
Figure 15 shows a less stringent statistic: the percent of facilities with any contraceptive supplies on hand on the day of the visit, by method. Under this definition of "availability", pills, condoms and IUDs appear to be equally available in 1989 and 1995. Depo Provera is slightly more available in 1995, and Norplant ${ }^{\circledR}$ implants are available in 6 percent of facilities (the pre-introductory trial was underway in one facility in 1989). The only notable change is a decrease in availability of foaming tablets, which were available in $80 \%$ of facilities in 1989 but only $15 \%$ of facilities in 1995.

\section{Figure 15 Percent of facilities with commodity stock on hand}

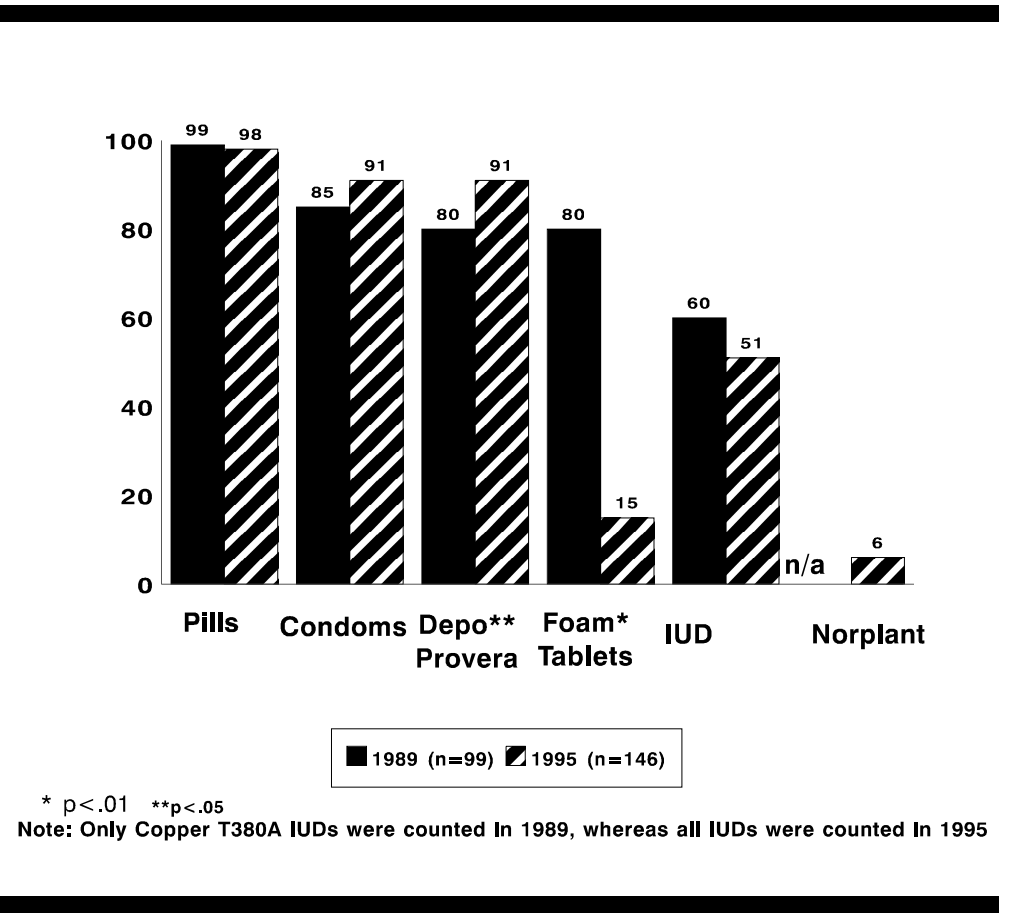

As for surgical methods, the 1989 Situation Analysis did not determine the number of facilities offering tubal ligation or vasectomy, but in 1995 tubal ligation was offered at $25 \%$ of facilities, and vasectomy at $11 \%$. In the section on "methods mentioned" below, we also see an increase in the number of clients informed about surgical methods, which may reflect an increase in the availability of these methods. A major recommendation of the 1989 study was to increase counseling on permanent methods and this has been acted upon by the Ministry of Health.

The increased availability of Depo Provera, Norplant ${ }^{\circledR}$ implants, and possibly sterilization, suggests improvements in the programme, if these more medically oriented technologies are provided with adequate quality. The substantial decrease in foam supplies dramatically decreases the only woman-controlled barrier method available and therefore may represent a deterioration of the programme. Given this exception, however, method availability appears to have increased.

b) Information, Education, Communication: The clinic-based IEC programme was rated low in 1989 based on availability of educational materials, and the low proportion of Facilities holding a health talk on the day of the research visit. However, it was noted that "weakness in the educational programme was somewhat balanced by the one-on-one client counseling process." 26

26 Page 96 in Miller, R., L. Ndhlovu, M. Gachara, and A. Fisher, 1992, "Situation Analysis Study of Kenya's Family Planning Program," in A. Jain, Ed., Managing Quality of Care in Population Programs, Kumarian Press. 
The data in Figure 16 suggest that there have been substantial improvements in the display of family planning posters and the availability of pamphlets and other educational material. However, there has been no observed improvement in the proportion of facilities providing health talks, nor in the provision of health talks that included family planning. This is despite the findings of a subsequent OR study that showed that health talks including family planning, when conducted with a display of methods, involvement of audiences, and answering of questions, resulted in substantial increases in the proportion of $\mathrm{MCH}$ clients adopting family planning. ${ }^{27}$ The IEC programme appears to have been strengthened in terms of availability of educational materials, but not in terms of health talks provided to waiting clients.

\section{Figure 16 Availability of IEC materials}

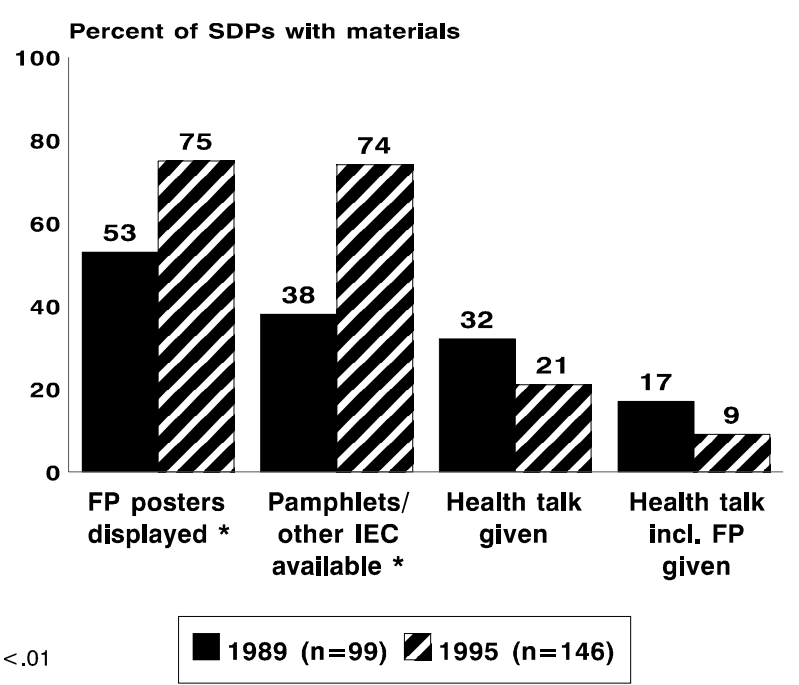

c) Supervision: The management/supervisory subsystem was rated low in 1989 based on the number of supervisory visits. As can be noted in Figure 17, these studies found no significant changes in the frequency of supervision provided.

d) Training: In the section on personnel and training, which was rated moderate in the 1989 study, researchers noted the shortage of staff receiving in-service training, and recommended that in-service training be increased. While the methodological differences between the two studies make the information on training difficult to compare, there has clearly

\section{Figure 17 Number of supervisory visits}

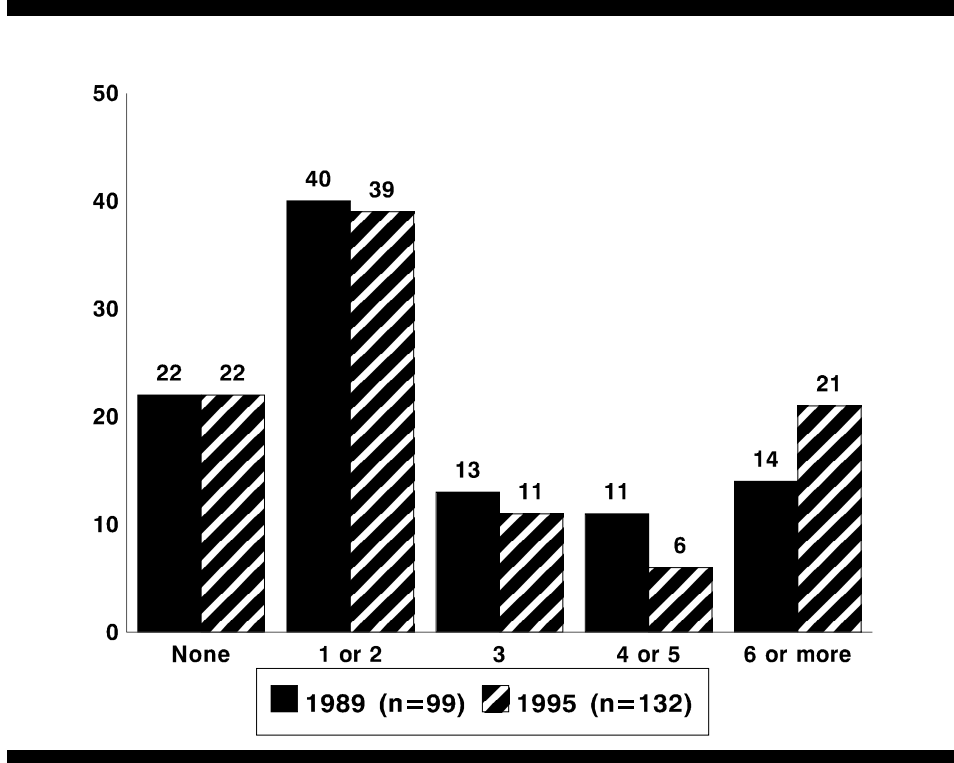

27 Miller, R., and R. Frerichs, 1992-1993, "An Integrated Approach to Operations Research for Strengthening Family Planning Programs: A Case Example in Kenya," International Quarterly of Community Health Education, 13:3, 183-199. 
been a dramatic increase in the proportion of nurses who received in-service training. In 1989 about 32 percent of nurses delivering family planning services reported having received inservice training; in 1995 it is about 60 percent.

e) Number of clients served, by method: The 1989 study demonstrated the dominant role of oral contraceptives in the Kenya programme, and of "the important role played by a minority of facilities in the sample." Further:

"While only about one-third (32 percent) of the facilities have no or few (under 20) clients for orals each month, about two-thirds (68 percent) have no or few clients for Depo Provera. Similarly, 28 percent offacilities serve over 100 clients monthly for orals, while only 4 percent of facilities serve that many clients for Depo Provera." (p. 100, Miller et al., 1992)

Figure 18 gives a comparison of the 1989 and 1995 distributions of facilities by the mean number of pill clients per month. Figure 19 provides the same information for the injectable. Taken together, the two graphs show: (1) a substantial reduction in the proportion of clinics that serve no clients for each method; (2) a large increase in the proportion of facilities serving 1-19 clients per month; and (3) large shifts in the proportions of facilities serving more than 100 clients per month - for oral contraceptives, this shift is downward from $28 \%$ to $13 \%$; for Depo Provera this shift is upward from $4 \%$ to $25 \%$. Note that the changes in the $100+$ category have a larger effect on the programme as a whole, since it involves so many more clients than the other categories.

This evidence suggests that there has been a substantial shift toward visits to supply Depo Provera and away from visits for the supply of oral contraceptives, which might be explained by an increase in the number of packets of pills distributed to clients at one time. More crucially, this change is

\section{Figure 18 Distribution of pill clients}

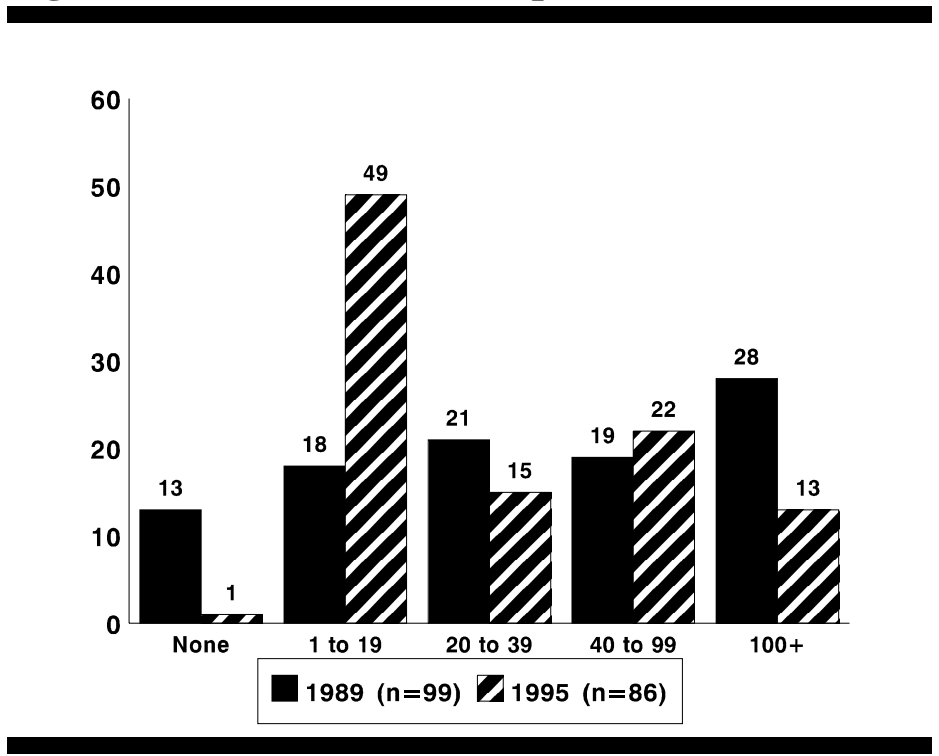

Figure 19 Distribution of injectable clients

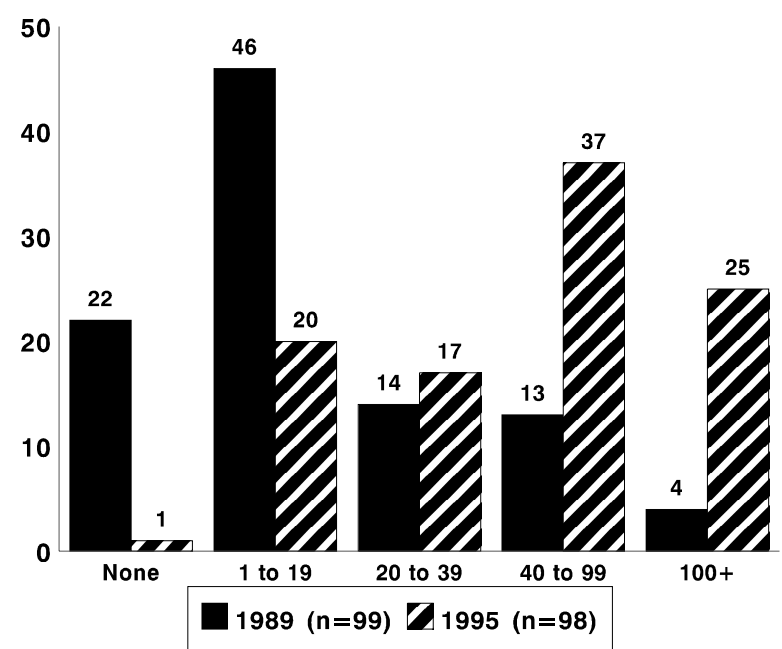


probably also related to US Federal Drug Administration (FDA) approval for Depo Provera in 1990, its subsequent availability under USAID funding, and a positive reaction to Depo Provera from Kenyan women.

\section{Quality of care}

a) Choice of Methods: Real client choice is difficult to measure. The Situation Analysis methodology provides only gross indicators of this important dimension of quality. Ideally, the methods discussed with clients would be welltailored to their circumstances, including their reproductive goals, breast-feeding status, partner relations and support, and of course the client's specific interest and wishes. In practice, we have some of this information on some of the clients and cannot judge Figure 20 methods mentioned to clients whether or not the methods

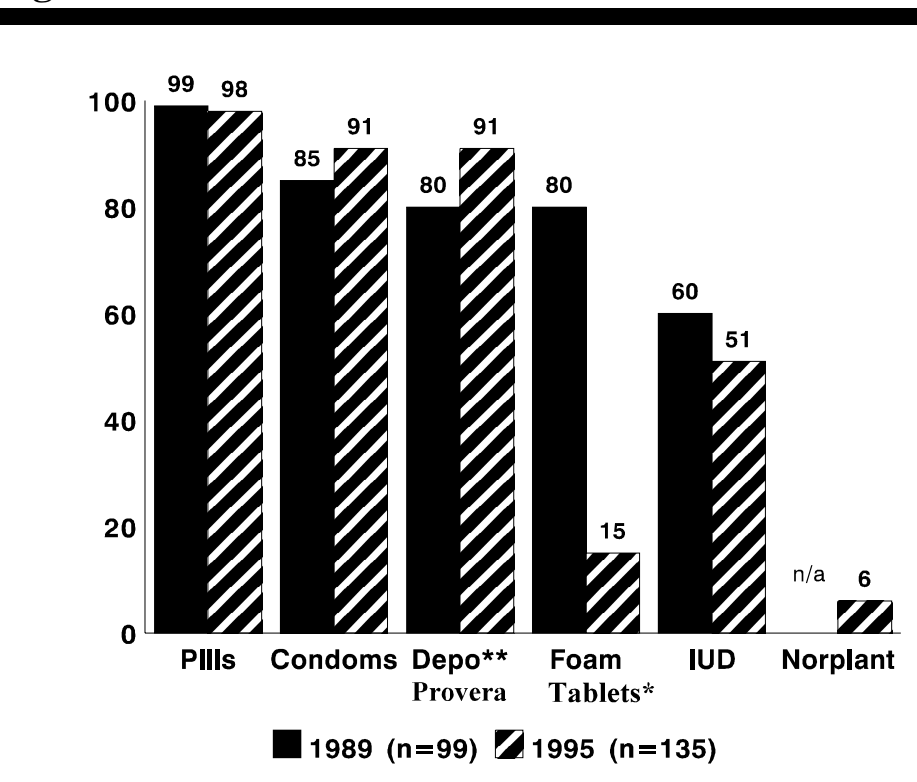
discussed with the clients are appropriate to their circumstances. For practical purposes, we are using the gross indicator of "methods mentioned", with the general but debatable assumption that more methods mentioned reflect increased choice. Figure 20 provides the proportion of clients in the two studies who heard about each method of family planning during counseling. Statistically significant changes include an increase in the proportion of clients hearing about tubal ligation and vasectomy, and a decrease in the proportion of clients hearing about foam/spermicides.

The mean number of methods mentioned in 1989 was 3.8; in 1995 this number was 4.2. Although this difference cannot be tested for statistical significance due to difficulties with the data, this does seem to suggest a rise in the number of methods mentioned to clients.

b) Information exchange: The 1989 Situation Analysis study judged information given to clients as "moderate" and recommended increasing information on side-effects and their management. There were substantial changes in the methodology and categories used to code the information provided to clients between the two studies. In 1989 the information was collected about the counseling process as a whole, whereas in 1995 the information relates only to the particular method the client accepted. 
Nevertheless, the results in Figure 21 may provide some insight about changes in information provided to clients ${ }^{28}$. A review of the training programmes for observers suggests comparability of four items: (1) the percent of clients informed "how to use" methods appears to be similar in both studies (88 percent in 1989; 84 percent in 1995); (2) information called

Figure 21

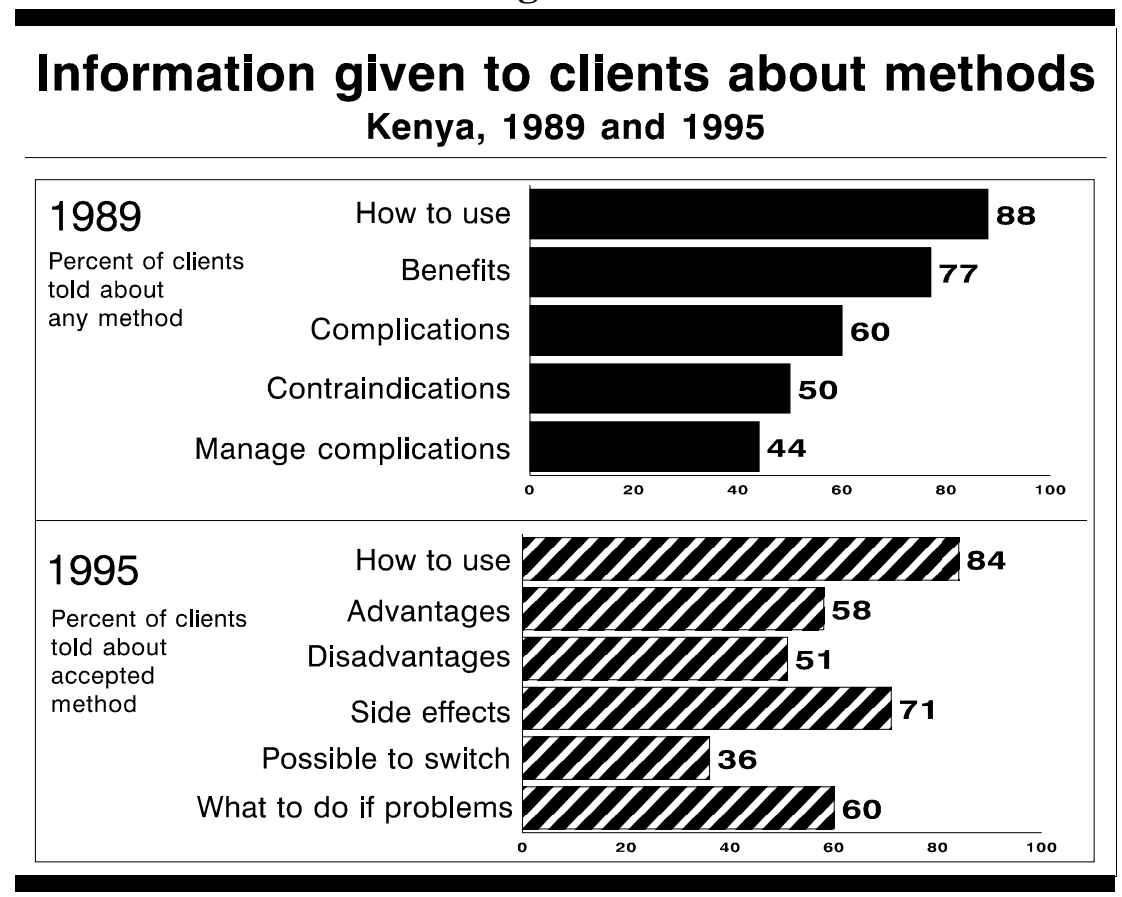

"benefits" in $1989(77 \%)$ was probably very similar to the information classified as "advantages" in 1995 (58\%); (3) information classified as "complications" in 1989 (60\%) is comparable to "side-effects" in 1995 (71\%); and (4) "manage complications" in 1989 (44\%) is similar to "what to do if problems" in $1995(60 \%)$.

Taken together, the data suggest that more clients heard about side effects and their management in 1995 (as was recommended after the 1989 study), fewer clients heard about the benefits of methods, and about the same proportion of clients heard about how to use methods. The increase in information about side effects and their management appears to reflect an increase in quality. The decrease in information about benefits may represent a decrease in quality; however, a more knowledgeable population that receives a more balanced presentation of benefits and side effects may not represent a decrease in quality. Interpreting this result will require further analysis and discussion.

28 Because the information was collected differently in 1989 and 1995, these results are not strictly comparable. No statistical tests are performed on this data. 
c) Integration of Services: In 1989, the researchers concluded that:

"Although FP services take place within an integrated context, relatively little integration of other health care was observed during a new client's first FP visit. In 85 percent of the 48 new client-provider interactions observed, no other health issue was discussed at the time of FP service..." (p 106, Miller et al., 1992)

By 1995, however, the proportion of clients who were observed to hear about at least one other health issue during their consultation increased significantly from 15 percent to 35 percent.

\section{CONCLUSIONS}

Programme managers, working with a substantial donor commitment, and no doubt in response to clients' wishes, appear to have:

- expanded the number of methods available;

- $\quad$ increased the availability of IEC materials;

- doubled the proportion of nursing personnel receiving refresher training;

- $\quad$ increased provision of Depo-Provera;

- not increased the amount of supervision provided to workers.

On quality of care:

- clients are hearing about more methods,

- are more frequently provided information on side-effects and how to manage them,

- increasingly hear about other health issues while receiving family planning services. 


\section{DISSEMINATION AND UTILIZATION OF THE STUDY RESULTS}

The results of this study have been formally presented twice to Kenyan programme managers and representatives of technical assistance and donor agencies working in Kenya. First, the data were presented in their "raw" form to a small group at the Data Interpretation Workshop (September 1995) who looked at the findings from a programmatic viewpoint, proposed additional analyses, and gave suggestions for further dissemination. Second, following from these discussions and suggestions a formal presentation of the final results for the overall study was made to a large audience of policymakers, managers, providers and donors during the Dissemination Seminar (March 1996).

The study was primarily undertaken to meet the needs for this type of data as expressed by programme managers from several organizations involved in the provision of family planning and other reproductive health services. Consequently, the information has been used, and continues to be used by these organizations on an individual basis.

\section{Ministry of Health}

The $\mathrm{MOH}$ is the main provider of family planning services in Kenya and to date has been the main user of these results. Although many of the findings have been used by the $\mathrm{MOH}$ management as general background information on the current status of the programme and its evolution since the first Situation Analysis study in 1989, the results have also been used in the preparation of two key documents.

Development of the MOH Reproductive Health Strategy. Late in 1995, the MOH started developing a reproductive health strategy which included the three critical areas of health services; maternal and child health, family planning and sexually transmitted diseases. In developing the health strategy, the Ministry was interested in finding out the extent to which the three services were integrated and how it could incorporate the clients' perspective in the design of this strategy. The most comprehensive information that was available then was provided by this study. A preliminary dissemination of the results had been conducted at the Silver Springs Hotel in Nairobi.

Development of the National Implementation Plan for the Kenyan Family Planning Programme for 1995 - 2000. In 1995, the MOH through the DFH, together with the NCPD and NGOs, was engaged in developing a five-year National Implementation Plan (NIP) for the Kenya Family Planning Programme. To improve access and quality of family planning services, the NIP Task Force identified three critical levels of involvement; at the community, the district and the health facility. At the health facility level, the MOH plans to work towards the development of standards for services offered at each type of facility. This will include personnel, equipment, and expendables, waiting time, cleanliness and responsiveness to clients needs. This study provided basic information to the NIP Task Force on many of these service elements at the health facility level. In addition, the study data showed the limited extent of integration of family planning with other reproductive health services (STD/AIDS , abortion). The use of the study results by the NIP Task Force was facilitated by the participation of representatives from six of the member organizations at different stages in the study, including its planning, data collection and interpretation. 
Dissemination of results to the Provincial and District levels. To date, dissemination and utilization of the results within the MOH has been limited to managers at the central level. Much interest in the results of the study has been expressed by managers at the provincial and district levels, and also at the individual facilities that participated in the study. As a first step to widen the dissemination of the results, this report is being circulated widely to $\mathrm{MOH}$ personnel at these levels. Secondly, plans are being made to hold some dissemination workshops at the provincial level to enable managers at the provincial and district levels to discuss the results amongst themselves, with their colleagues from the central level, and with other interested parties.

Development of a study to better understand the integration of family planning and MCH services at MCH/FP units. The efficient and effective integration of services is a key concern for programme managers in Kenya, as elsewhere, but little is known about the interaction between the provision of $\mathrm{MCH}$ services and the provision of family planning services at the $\mathrm{MCH} / \mathrm{FP}$ units of these facilities. Results from this study have suggested that there is untapped potential for a greater provision of family planning information and services to $\mathrm{MCH}$ clients attending these facilities, and so a follow-on study is currently being implemented to explore what is currently happening at a sub-sample of these facilities.

\section{Other organizations}

Among the other organizations that constituted the planning team for the study and whose facilities were included in the study sample, several have already used the data for planning the future directions for their programmes, and for identifying areas that need additional funding.

Early in 1996, Marie Stopes International requested data from the study specifically for their health facilities, and assistance in analyzing the data and preparing a summary report. Two of the researchers who had participated in study fieldwork were identified and prepared the report. This document was then used by Marie Stopes for writing a project proposal submitted to the World Bank.

In October 1996 a workshop was held by the Nairobi City Council with the Africa OR/TA Project II and Pathfinder International to analyze the data specifically for the city's 44 health facilities, all of which had been included in the study. The NCC and Pathfinder International were interested in assessing the impact of several service delivery interventions, including improving IEC activities and strengthening equipment supplies, that had been developed and introduced as a result of the NCC's 1991 Situation Analysis study. Donors that fund the NCC's health programmes (e.g. USAID, UNFPA) also participated. The workshop was attended by over 40 participants (including facility service providers and managers) and provided a forum for discussing a number of problems that are faced at operational levels. Recommendations were made about different aspects of the NCC programme and managers are currently working towards implementing these recommendations. As part of this activity, selected staff at the NCC were trained in basic data analysis and presentation methods using computer programs. 
The other two major service delivery organizations involved in the study, CHAK and FPAK, have expressed interest in looking at the data for their facilities but to date have not yet done so. The data sets are also being made available to AVSCI and JHPIEGO, two of the technical assistance organizations that have participated in the study and which provide substantial assistance to many of the facilities included in the study.

The family planning programme in Kenya is attracting a lot of attention worldwide following the recent precipitous decline in the country's fertility rate. Through it's regional and international programme of activities, the Africa OR/TA Project II is disseminating the results of this study to those interested through several channels including the distribution of this report, presentations of papers at conferences, and use of the data in comparative analyses. 


\section{APPENDIX I}

In calculating the sample size, the attribute of interest was considered to be the proportion of SDPs having a high client load, the reason being that it is felt that these clinics may have higher quality of care. ${ }^{29}$ Results of prior studies, have shown that approximately 25 percent of clinics in a programme serve most of the family planning clients (approximately 75 percent) and thus have the highest client load. ${ }^{30}$ Thus, using the standard formula for calculating a sample size, we have

$$
\mathrm{n}=\mathrm{Z}^{2} \mathrm{pq} / \mathrm{d}^{2}
$$

where: $\mathrm{Z}=$ standard normal deviate with a value of 1.96

$p=0.25$ is the estimated proportion of health facilities with an acceptable level of quality

$q=1-p=0.75$ is the estimated proportion without attribute

$\mathrm{d}=0.05$

Using the above formula, the calculation yields $n=288$. Applying a correction factor $\mathrm{n} /(1+\mathrm{n} / \mathrm{N})$ for a population size of less than 10,000 , a corrected sample size of 219 is obtained.

Of approximately 966 SDPs that deliver family planning services, 71 percent are government and the rest are NGO. Using these proportions, the sample size of 219 is divided into 156 government and 63 NGOs. Table a shows the calculation of total sample sizes for hospitals, health centres and dispensaries.

The stratified random sampling scheme with proportional allocation is used for calculating sample sizes $(43,43,69)$ for hospitals, health centres and dispensaries. ${ }^{31}$ The number of new acceptors are used for weighting. Figures for standard deviations from the means of new acceptors of 1513, 290 and 352 for hospitals, health centres and dispensaries respectively were obtained from comparative data from Tanzania since the data for Kenya was incomplete. The service statistics from health facilities in Tanzanian were found to be comparable for use in the Kenyan situation.

29 Op.cit. Mensch, et. al.

30 Fisher, Andrew in "Conference Proceedings and Papers" The Population Council, Nairobi 4-7 October, 1993.

31 page 526 in Snedecor, W. George and William G. Cochran (1968) "Statistical Methods" Oxford \& IBH, New Delhi (1968). 
Table a: Determination of sample sizes for government and NCC clinics by different facility types.

\begin{tabular}{||l|l|l|l|l|l||}
\hline $\begin{array}{l}\text { Facility Type } \\
\text { (Stratum) }\end{array}$ & $\begin{array}{l}\text { Number of } \\
\text { SDPS } \\
\left(\mathrm{N}_{\mathrm{h}}\right)\end{array}$ & $\begin{array}{l}\text { Standard } \\
\text { Deviation } \\
\left(\sigma_{\mathrm{h}}\right)\end{array}$ & $\mathrm{N}_{\mathrm{h}} \sigma_{\mathrm{h}}$ & $\begin{array}{l}\text { Relative } \\
\text { Sample Sizes } \\
\mathrm{N}_{\mathrm{h}} \sigma_{\mathrm{h}} / \Sigma \mathrm{N}_{\mathrm{h}} \sigma_{\mathrm{h}}\end{array}$ & $\begin{array}{l}\text { Actual } \\
\text { Samples }\end{array}$ \\
\hline Hospital & 73 & 1513 & 110449 & 0.276 & 43 \\
\hline Health Centre & 386 & 290 & 111940 & 0.279 & 43 \\
\hline Dispensary & 507 & 352 & 178464 & 0.445 & 69 \\
\hline TOTAL & $\mathbf{9 6 6}$ & & $\mathbf{4 0 0 8 5 3}$ & & $\mathbf{1 5 5}$ \\
\hline
\end{tabular}

For example, we use the formula $\mathrm{n}_{\mathrm{h}}=\mathrm{nN}_{\mathrm{h}} \sigma_{\mathrm{h}} / \Sigma \mathrm{N}_{\mathrm{h}} \sigma_{\mathrm{h}}$ (for $\mathrm{h}=1,2$ and 3) to calculate the sample sizes shown in the Table b below. The variables take the standard definitions; that is,

$$
\begin{aligned}
& \mathrm{N}=\text { population size } \\
& \mathrm{n}=\text { sample size } \\
& \sigma=\text { standard deviation and } \\
& \mathrm{h}=\text { stratum (hospital, health centre and dispensary) }
\end{aligned}
$$

The final sample determination for the government and NGOs is shown in Tables b and c respectively. Within each type of sector, the final unit selection was randomly conducted.

Though a total sample of 219 government and NGO SDPs constituted the core sample, an additional number was requested by the Nairobi City Council, Pathfinder International and AVSC. For the Nairobi City Council clinics, a census was conducted while purposive samples were requested for Marie Stopes and Family Planning Association of Kenya (FPAK) facilities. Health facilities that were purposively sampled were excluded from the analysis presented in this report. A total of 264 facilities were visited during field work; of this number, 254 form the basis of this report. 
Table b: Distribution of the total population of, and sample of, government and NCC service delivery points by province.

\begin{tabular}{|c|c|c|c|c|c|c|c|}
\hline \multirow[b]{2}{*}{ PROVINCE } & \multicolumn{3}{|c|}{$\begin{array}{l}\text { Total Population Size of Govt. \& } \\
\text { NCC SDPs }\end{array}$} & \multicolumn{3}{|c|}{$\begin{array}{l}\text { Sample Sizes for Govt. \& NCC } \\
\text { SDPs }\end{array}$} & \multirow[b]{2}{*}{ TOTAL } \\
\hline & Hospital & $\begin{array}{l}\text { Health } \\
\text { Centre }\end{array}$ & $\begin{array}{l}\text { Dispensar } \\
\mathrm{y}\end{array}$ & Hospital & $\begin{array}{l}\text { Health } \\
\text { Centre }\end{array}$ & $\begin{array}{l}\text { Dispensar } \\
\mathrm{y}\end{array}$ & \\
\hline Nairobi & 0 & 9 & 41 & 0 & 1 & 6 & 7 \\
\hline Central & 10 & 48 & 76 & 6 & 5 & 10 & 21 \\
\hline Coast & 9 & 39 & 76 & 5 & 4 & 10 & 19 \\
\hline Eastern & 14 & 59 & 114 & 8 & 7 & 16 & 31 \\
\hline Nyanza & 14 & 74 & 91 & 8 & 8 & 12 & 28 \\
\hline R/Valley & 23 & 105 & 85 & 14 & 12 & 12 & 38 \\
\hline Western & 3 & 52 & 24 & 2 & 6 & 3 & 11 \\
\hline TOTAL & 73 & 386 & 507 & 43 & 43 & 69 & 155 \\
\hline
\end{tabular}

Table c: Distribution of NGO facilities (total population and sample) by province and facility type.

\begin{tabular}{||l|c|c|c|c||}
\hline & \multicolumn{2}{|c|}{ Total Population } & \multicolumn{2}{c|}{ Sample size } \\
\hline PROVINCE & Hospital & $\begin{array}{l}\text { Health centre/ } \\
\text { dispensary }\end{array}$ & Hospital & $\begin{array}{c}\text { Health centre/ } \\
\text { dispensary }\end{array}$ \\
\hline Nairobi & 0 & 29 & 0 & 5 \\
\hline Central & 3 & 37 & 2 & 6 \\
\hline Coast & 2 & 20 & 2 & 3 \\
\hline Eastern & 5 & 56 & 4 & 9 \\
\hline Nyanza & 4 & 51 & 9 & 5 \\
\hline Rift Valley & 11 & 31 & 4 & 4 \\
\hline Western & 5 & 29 & 24 & 40 \\
\hline TOTAL & 30 & 253 & 3 & 5 \\
\hline Note: It was not possible to make a distinction between health centres and dispensaries. \\
\hline
\end{tabular}




\section{APPENDIX 2}

\section{PARTICIPANTS FOR THE KENYA SITUATION ANALYSIS STUDY TEAM SUPERVISORS}

Fatuma Juma Ali

Milka Adoyo Juma

Eunice Munanie

Lucy Wangui Njeru

Pricilla Atwani Akwara

Jennifer Katunge Kioko Liku

Dorcas Wambui Kungu

Elizabeth Wairimu Mugwe

Emmanuel Sigar Adienge

Millie Chepkemoi Obel

\section{DATA COLLECTORS}

Mercellus Ayoma-Matunga

Magdalene Mumbi Kyalo

Joel Kinyua

Julius Kobia Mwenda

Salome Nyatetu Waruingi

Hazel Phoebe Ogolla

Carey Francis Ayuka

Miriam Muthikwa Mutua

Alice C Misoi

Lilian Chepkorir Rono

Miriam Fancie Ondiso Wa-Tindi

Jane Jerotich Kotut

Dinah N Mogaka

Helen Muhonja Wanjala

Alice Waruguru Irungu

Sarah Cirindi Riungu

Esther R Anzenze

Dorsila Imali Sande

Rachel Oketch Bosibori

Rose M Mosongo

DATA ENTRY OPERATORS

Boniface Kitungulu

Lucy Nganga 